\title{
Propriedades físico-estruturais do solo em área sob processo de degradação próximo
} às margens do rio Balsas-MA

Physical-structural properties of soil in an area under degradation process near the margins of the Balsas-MA river

Propiedades físicas y estructurales del suelo en una zona en proceso de degradación cerca de las orillas del río Balsas-MA

Recebido: 23/12/2021 | Revisado: 30/12/2021 | Aceito: 06/01/2022 | Publicado: 09/01/2022

\author{
Marcos Vinicius Elias Martins \\ ORCID: https://orcid.org/0000-0002-5243-9416 \\ Universidade Federal do Maranhão, Brasil \\ E-mail:vfederal@hotmail.com \\ Maria Laiane do Nascimento Silva \\ ORCID: https://orcid.org/0000-0002-5942-0603 \\ Universidade Federal do Maranhão, Brasil \\ E-mail: laiane.maria@ufma.br
}

\begin{abstract}
Resumo
É notável que nos últimos anos, há uma recorrência cada vez maior quanto às atividades antrópicas que impactam de forma direta ou indireta as áreas ambientais. Com base nisso, o presente trabalho visa apresentar os dados de uma determinada área nas proximidades do bairro Trizidela no município de Balsas-MA que está em processo de degradação que se localiza às margens do rio Balsas, apresentando um levantamento de dados e informações sobre as propriedades físico-estruturais do solo em estudo. $\mathrm{O}$ trabalho realizado possui uma metodologia do tipo quali-quanti avaliativa e a análise dos resultados foi feita de modo a expor as inter-relações existentes entre as propriedades físico-estruturais do solo, a avaliação da qualidade estrutural e o diagnóstico rápido de estrutura do solo (DRES), obtendo-se como base para o entendimento dos processos de degradação ambiental presentes na área. Como principais resultados, destacam-se a avaliação das propriedades físico-estruturais do solo que indica uma qualidade física e estrutural superior para o ponto P1, consideravelmente mais conservada. Porém, os dados para os pontos P2 e P3 não mostraram a severidade da degradação observada no local, necessitando de uma análise mais aprofundada em relação aos outros atributos e propriedades do solo e inclusive por métodos diferentes. Por meio do DRES, foi possível comprovar a qualidade estrutural superior do ponto de coleta P1 em relação aos P2 e P3, mas diferente da avaliação dos atributos físicoestruturais, mostrou a degradação avançada que esses dois últimos pontos se encontram.
\end{abstract}

Palavras-chave: Degradação ambiental; DRES; Qualidade física do solo; Recuperação de áreas degradadas.

\begin{abstract}
It is notable that in recent years, there is an increasing recurrence of anthropic activities that directly or indirectly impact environmental areas. Based on this, this paper aims to present data from a particular area near the neighborhood Trizidela in the municipality of Balsas-MA that is in the process of degradation that is located on the banks of the Balsas River, presenting a survey of data and information about the physical and structural properties of the soil under study. The work carried out has a quali-quantitative evaluative type methodology and the analysis of the results was done in order to expose the existing interrelationships between the physical-structural properties of the soil, the evaluation of the structural quality and the rapid diagnosis of soil structure (DRES), obtaining as a basis for understanding the processes of environmental degradation present in the area. As main results, we highlight the evaluation of the physicalstructural properties of the soil that indicates a superior physical and structural quality for point P1, considerably more conserved. However, the data for points P2 and P3 did not show the severity of the degradation observed at the site, requiring further analysis in relation to the other soil attributes and properties and even by different methods. Through the ESRD, it was possible to prove the superior structural quality of the collection point P1 in relation to P2 and P3, but different from the evaluation of the physical-structural attributes, it showed the advanced degradation that these last two points are.
\end{abstract}

Keywords: Environmental degradation; ESRD; Soil physical quality; Recuperation of degraded areas.

\section{Resumen}

Es notable que en los últimos años se repitan cada vez más las actividades antrópicas que impactan directa o indirectamente en las áreas ambientales. En base a esto, el presente trabajo tiene como objetivo presentar los datos de 
una zona concreta cercana al barrio de Trizidela en el municipio de Balsas-MA que se encuentra en proceso de degradación que se ubica en la ribera del río Balsas, presentando un levantamiento de datos e información sobre las propiedades físicas y estructurales del suelo en estudio. El trabajo realizado cuenta con una metodología del tipo cualiquanti evaluativa y el análisis de los resultados se realizó con el fin de exponer las interrelaciones existentes entre las propiedades físico-estructurales del suelo, la evaluación de la calidad estructural y el diagnóstico rápido de la estructura del suelo (DRES), obteniendo como base para la comprensión de los procesos de degradación ambiental presentes en la zona. Como principales resultados, destaca la evaluación de las propiedades físico-estructurales del suelo que indica una calidad física y estructural superior para el punto P1, considerablemente más conservado. Sin embargo, los datos de los puntos P2 y P3 no mostraban la gravedad de la degradación observada en el lugar, lo que requería un análisis más profundo en relación con los demás atributos y propiedades del suelo, e incluso mediante métodos diferentes. Mediante el ESRD, se pudo comprobar la calidad estructural superior del punto de captación P1 en relación a P2 y P3, pero a diferencia de la evaluación de los atributos físico-estructurales, mostró la avanzada degradación en que se encuentran estos dos últimos puntos.

Palabras clave: Degradación ambiental; ESRD; Calidad física del suelo; Rehabilitación de zonas degradadas.

\section{Introdução}

São inúmeras e cada vez mais recorrentes as ações antrópicas que influenciam de maneira direta ou indireta o desgaste e o impacto em áreas ambientais. Com o aumento cada mais incisivo e exponencial da agricultura para o suprimento da alimentação humana (que cresce cada vez mais), o zoneamento urbano de novas áreas e o avanço da pecuária, medidas se fazem necessárias para impedir ou mitigar os processos de degradação em andamento ou já realizados.

Entre os dois ambientes que são acometidos por tais ações realizadas está o aquático e o terrestre. O ambiente aquático sofre por conta de fatores relacionados aos despejos de efluentes e perda de mata ciliar e o ambiente terrestre pela retirada da cobertura vegetal que por sua vez pode resultar em desequilíbrio ecológico (atrelado à ambos os ambientes) e incapacidade de produção (MARTINS et al, 2021).

Ainda atrelado a esta problemática está o fato de que muitas dessas áreas se encontram próximas a córregos como rios, riachos ou afluentes o que gera pode vir a gerar um dano ainda mais severo ao ecossistema presente naquele ambiente. Conhecer o local e entender os problemas que ali ocorrem por mecanismos científicos é o primeiro passo na busca para a recuperação dessa área.

O conhecimento em torno dos dados que são obtidos sobre um determinado solo apresenta muito mais do que uma visão a olho nu pode constatar. As informações obtidas em pesquisas desse porte revelam uma interpretação mais concisa e verídica sobre a forma, as características, o resultado da influência de fatores externos ao ambiente e o que pode ser feito para remediar o solo comprometido.

O entendimento das propriedades físico-estruturais do solo apresenta-se como primordial para a proposição de medidas de recuperação ambiental, uma vez que, comanda os fluxos de água, gases, calor, organismos e poluentes no solo. Quando tais processos ocorrem de forma incorreta, os danos ocorrem não somente no local em si, mas permeiam-se por toda a área.

Localizada na região sul do estado do Maranhão a cidade Balsas possui uma forte atividade em torno do agronegócio o que, por sua vez, gerou e ainda gera o desenvolvimento do município (Formiga, 2021). No entanto, como o avanço desse desenvolvimento que ocorreu sem um olhar voltado para o que tais atividades poderiam gerar ao meio ambiente, o que se têm são áreas que foram comprometidas por conta de atividades que prejudicaram determinados ambientes.

Com base nisso, o presente trabalho visou apresentar um levantamento de dados e informações sobre as propriedades físico-estruturais do solo de uma determinada área localizada nas proximidades do bairro Trizidela às margens do rio BalsasMA reatando as principais particularidades em relação ao estudo. 


\section{Revisão de Literatura}

O avanço tecnológico permitiu ao ser humano o desenvolvimento centros urbanos bem como a possibilidade de melhoria quanto à produção de alimentos que pudessem sanar o mercado e por sua vez os seus respectivos consumidores, ou seja, alimentar a população. No entanto, a observação dentro de um contexto histórico, permite ao observador perceber que durante esse processo houve em inúmeras partes um certo descuido quanto ao meio ambiente em que tal processo era realizado (Sovis, 2021).

Conforme Castro (2021), seja por questões relacionadas ao processo de produção de comodities oriundas do agronegócio, ou pelo uso e ocupação do solo de forma inapropriada para os processos de urbanização, as localidades onde ambas as atividades se alocam acabam por receber uma infinidade de malefícios que inicialmente prejudicam o próprio meio, mas que por conseguinte afetam às pessoas que ali convivem.

Existe uma necessidade atual de entender o comportamento dos mais variados ambientes visando os três pilares de sustentação da própria Engenharia Ambiental que seria o econômico, o social e o ambiental. Essa perspectiva remonta a ideia de que o desenvolvimento não é visto como uma forma ruina para a sociedade atual, mas sim, como esse processo ocorre e o que ou a quem afetam (Melo e Robeto, 2018).

É dentro desse paradigma que o presente trabalho se norteia, afim de possibilitar uma compreensão do próprio local por meio dos resultados que serão obtidos e em torno das análises do solo da área delimitada, afim de compreender a forma como as atividades antrópicas realizadas naquele determinado meio se alteraram e consequentemente o modificaram.

\subsection{Conceitos e características dos solos do Brasil, Nordeste e Maranhão}

\subsubsection{Brasil}

O levantamento de qualquer que seja o estudo ou em qualquer que seja a área se faz por necessidade a compreensão sobre o que é dito e o que é explicado. Não diferente da narrativa apresentada, o primeiro conceito ao qual se faz necessário compreender é o conceito do que é o solo, sendo assim, conforme Santos et al (2018, pg. 27):

O solo é uma coleção de corpos naturais, constituídos por partes sólidas, líquidas e gasosas, tridimensionais, dinâmicos, formados por materiais minerais e orgânicos que ocupam a maior parte do manto superficial das extensões continentais do nosso planeta, contêm matéria viva e podem ser vegetados na natureza onde ocorrem e, eventualmente, terem sido modificados por interferências antrópicas.

Uma vez entendido o que é o solo, se faz necessário entende-lo dentro das delimitações do território brasileiro (trazendose para um ponto de vista generalizado). Conforme Oliveira et al (2014), o primeiro ponto relevante às principais características do solo brasileiro remete ao fato do Brasil ter dimensões continentais, o que faz com que o país possua uma ampla diversidade de pedoambientes e os mais variados fatores que afetam os processos de formação dos solos.

Conforme a Embrapa (2021), o Brasil apresenta 13 classes de solos contidas no Sistema Brasileiro de Classificação de Solos (SiBCS), constata-se a influência desses fatores através da grande variabilidade das características químicas, físicas e morfológicas.

Alguns tipos de solos predominam em território brasileiro, como é o caso dos Latossolos, Argissolos e Neossolos, que no conjunto se distribuem em aproximadamente 70\% do território nacional. Conforme Ramiro (2019), as classes Latossolos e Argissolos ocupam aproximadamente 58\% da área e são solos profundos, altamente intemperizados, ácidos, de baixa fertilidade natural e, em certos casos, com alta saturação por alumínio.

Os Latossolos e Argissolos predominam em âmbito nacional, se comparados com as demais classes de solo. São solos que em sua maioria apresentam baixa fertilidade natural, no entanto, devido ao maior desenvolvimento e estabilidade estrutural 
são muito visados para atividades agrícolas. Para Almeida (2019), com o desenvolvimento da Ciência do Solo no Brasil, práticas agrícolas foram desenvolvidas que permitiram a exploração dessas áreas, como por exemplo, a calagem que é uma prática que adiciona cálcio e magnésio ao solo enquanto corrige a acidez deste.

Ainda dentro dessa descrição cabe-se ressaltar que também ocorrem solos de média a alta fertilidade, em geral pouco profundos em decorrência de seu baixo grau de intemperismo. Para Santos et al (2018), estes se enquadram principalmente nas classes dos Neossolos, Luvissolos, Planossolos, Nitossolos, Chernossolos e Cambissolos.

Um ponto que vale salientar é que o território brasileiro encontra-se quase todo na zona tropical e tem um relevo que desde o final do Cretáceo não sofreu grandes movimentações (Novaes Filho et al, 2007). Assim, a natureza da rocha e o relevo têm importância secundária na formação dos solos, sendo o clima fator predominante na pedogênese.

As atribuições mais específicas em torno das características do solo região e área em estudo virão nos tópicos seguintes, uma vez que se faz necessário, inicialmente, o entendimento geral sobre o solo brasileiro para em seguida compreender a dinâmica existente no solo em estudo.

\subsubsection{Os solos da região Nordeste}

A maior parte das informações presentes nesse tópico são embasadas no conteúdo presente no livro intitulado: Uso Agrícola dos Solos Brasileiros de Manzato e et al (2002), esse livro é um norte quanto à percepção das principais características que propiciam uma distinção quanto às regiões do país, por isso existe uma importância em destacar a sua posição nessa base de revisão, principalmente para o tópico apresentado.

Sendo assim, conforme Manzato (2002), o primeiro ponto importante é a divisão das zonas que se encontram na região nordeste que são: Litorânea, Agreste e Sertão, as quais, totalizadas, ocupam $1.582 \mathrm{mil} \mathrm{km}^{2}$. Estas duas últimas se caracterizam pelo clima semiárido, abrangendo, aproximadamente, $70 \%$ da área daquela região, bem como $63 \%$ da população nordestina. Uma das principais características dessa região está relacionada a sua incrível variabilidade dos solos ali encontrados bem como as condições ambientais, estes solos possuem uma predisposição e um grande potencial para os mais variados tipos de produção.

Considerando apenas duas grandes faixas - a úmida (Litorânea) e a semi- árida - seria possível caracterizar aproximadamente os solos de cada uma delas de acordo com Souza (1979). A primeira faixa revela solos bem diferenciados. Compreende grande parte do Maranhão, amplas áreas do Piauí e a faixa costeira que vai do Rio Grande do Norte até o sul da Bahia, incluindo os Tabuleiros Costeiros. Sobre ela repousa a economia agrícola do litoral úmido - a cana-de-açúcar, o cacau, as frutas, o arroz, etc. - em substituição às matas desaparecidas.

Os solos aí são de profundidade variada, dotados de boa precipitação anual, e tiveram sua fertilidade reduzida graças ao uso agrícola contínuo e à grande pluviosidade, favorecendo a lixiviação e a erosão. Conforme a descrição apresentada por Oliveira, Jacomine e Camargo (2000), é nestas condições que dominam os Latossolos que ocorrem em relevos planos e suaves ondulados e ocupam 488 mil km², correspondendo a 31\% da área total do Nordeste.

A Segunda, zona semi-árida (Agreste e Sertão), com índices de pluviosidade mais baixos, abrange várias áreas do interior do Nordeste. Em geral, os solos aí são mais rasos, dotados de boa fertilidade natural, tendo em vista a retenção de elementos minerais. Sua extensão compreende a maior parte do polígono das secas.

Segundo Manzato (2002, pg. 178):

Ocupando as áreas mais movimentadas, aparecem tanto os Argissolos com baixa reserva de nutrientes, distribuídos por 290 mil km2 (18,4\%), como os Luvissolos; esses, de elevada fertilidade natural, ocupam 107 mil km2. Nestas condições ocorrem, também, os Neossolos, solos jovens que se diferenciam em Litólicos, Quartzarênicos, e Regolíticos, ocupando $28,5 \%$ da região nordeste (451 mil km2). 
Por sua vez, em relevo plano e suave ondulado, destacam-se os Planossolos e Plintossolos, solos mal drenados, que costumam ser mais usados para fins de pastagem. Os solos do Nordeste se diversificam segundo os variados fatores de formação que lhes deram origem. Conforme Almeida (2019), o que se percebe é que dentro dessa variabilidade existem solos que são considerados mais ricos ou aqueles mais pobres, bem como aqueles que são oriundos de processos erosivos ou por incidência de fogo.

Um outro ponto, oriundo do trabalho de Lima e Melo (2007), mostrou que a irracionalidade quanto ao uso do solo pela agricultura itinerante tem sido a causa mais importante de sua devastação. $O$ que percebe-se é que a região nordeste tem uma vastidão territorial de solo que deveria suprir as necessidades da população que se encontra nessa região, no entanto, o que se percebe é o acúmulo de grande propriedades de terra nas mãos de uma risível parcela da população o que gera um alto lucro na mão de um pequeno grupo de indivíduos.

\subsubsection{Os solos do Maranhão}

Conforme Montes (2007,) um ponto bastante interessante sobre o estado do Maranhão é que mesmo ele fazendo parte da região Nordeste, que apresenta um clima semiárido (em sua maior parte) o presente estado é ocupado pela vegetação de floresta, observando-se uma transição a Amazônia que possui um clima mais úmido que clima o semiárido presente da região Nordeste.

Para Santos et al (2018), é por meio dessa localização transicional que encontra-se no estado condições socioeconômicas interessantes, pois permitiriam o avanço na produção e avanço do agronegócio em boa parte do estado, principalmente na região Sul do estado, compreendida na faixa de expansão agrícola conhecida como MATOPIBA (Maranhão, Tocantins, Piauí e Bahia).

O estado do Maranhão apresenta cinco regiões que se definem por condicionantes regionais semelhantes sendo: geomorfológico, geológico e bioclimático (Montes, 2007). Em sua totalidade, as regiões englobam 28 sistemas naturais e tais sistemas criam as unidades elementares de análise denominadas geofáces, que traduzem as características tanto do solo como do relevo.

O trabalho desenvolvido pela EMBRAPA (2018), em conjunto com o Ministério da Agricultura apresentou um zoneamento quanto aos principais solos, em termos de extensão, que estão localizados no estado, dentro desse estudo se averigua ainda a importância de destacar a influência que o clima, os períodos de sazonalidades e as interferências antrópicas possuem sobre o processo de formação ou de danificação de cada um desses solos.

Sendo assim, como mencionado no parágrafo anterior, os solos identificados pela EMBRAPA (2018), em termos de extensão dentro do território do estado são (Ver Anexo II): Latossolos Amarelos (Micos e Distróficos), Podzólicos VermelhoAmarelos (Micos, Distróficos e Eutróficos), Plintossolos (Micos e Distróficos), Neossolos Quartzarênicos e Neossolos Litólicos (Neossolos Quartzarênicos e Neossolos Litólicos). Em menores proporções encontram-se ainda os seguintes solos: Latossolos Vermelho-Escuros, Latossolos Roxos, Nitossolo, Podzólico, Cambissolos, Vertissolos, Gleissolos, Planossolos, Solos Aluviais e Solos Indiscriminados de Mangues.

Conforme Filho, Bueno e Valladares (2020):

Os solos do Estado do Maranhão são, em geral, oriundos de formações sedimentares, apresentando elevado grau de intemperismo, elevada acidez e baixas capacidade de troca catiônica e saturação por bases e textura variando entre arenosa a argilosa. Os Aluviões Fluviomarinhos da Baixada Maranhense é uma região influenciada pelo Golfão Maranhense, com solos hidromórficos de textura muito argilosa, elevados teores de $\mathrm{Ca} 2+, \mathrm{Mg} 2+, \mathrm{Al} 3+$, elevada CTC e baixa saturação por bases.

O que se percebe é que fato abordado pelos autores quanto as características presentes nos solos maranhenses quanto a sua utilização é que a principal limitação, para a maioria dos solos dessa ordem conforme Túlio et al (2019), está associada a 
baixa fertilidade natural, contudo, apresentam elevado potencial agrícola, tendo em vista que a elevada profundidade associada ao relevo plano onde ocorrem, favorecem a mecanização, a infiltração e o armazenamento de água, minimizando a ação da erosão.

Os solos da região Sul do Maranhão apresentam ou tendenciam a ter as caraterísticas apresentadas por Túlio et al (2019), no tópico 2.3, enfatizando que estes solos possuem, no geral, uma baixa fertilidade natural, contudo, apresentam elevado potencial agrícola, tendo em vista que a elevada profundidade associada ao relevo plano onde ocorrem, favorecem a mecanização, a infiltração e o armazenamento de água, minimizando a ação da erosão.

\subsection{O solo: serviços ecossistêmicos}

A premissa em torno da importância e do solo é que ele é um dos os meios de sobrevivência e por conseguinte para a existência para o ser humano. Conforme Brasil (2021), suas respectivas atribuições vão além da aplicação do verbo "saciar" quanto à fome do que foi plantado pois, além de propiciarem o princípio e fundamentação do viver humano, estabelecem a normativa para o cunho social.

Mas o que isso quer dizer? Conforme Ramos et al (2018), em linhas gerais, isso especifica e quantifica não somente sua importância em um único setor como o agronegócio, por exemplo, isso porque o ser humano, em sua essência, assim como necessita de quantidades específicas de diárias de água também precisa de determinadas quantidades de alimento para a sua existência.

Sendo assim, para Santos e Aquino (2016), o seu controle e seu respectivo uso vão além da admiração quanto à sua forma natural e interligam-se a todas as principais áreas que realizam o bom funcionamento da roldana social. É dentro desse primeiro viés que cabe-se enfatizar suas respectivas atribuições e contribuições para o solo.

O solo é uma peça chave para o desenvolvimento das sociedades e do próprio sentido que atribui a característica de planeta com vida dentro de uma prospecção espacial. Isso se deve ao fato de que o solo saudável possui as propriedades que permitem o desenvolvimento da vida, tanto dentro como fora do meio (Ribeiro E Rolim, 2017).

O solo permite, como já citado anteriormente, a sobrevivência por meio de seu trato de praticamente todos os seres vivos como espécie, e focando no cunho social, para Lima e Lima (2008), permite que as sociedades se desenvolvam, permite o crescimento dessas mesmas sociedades bem como o sentido de sua busca tanto para o presente, como em meios atuais, para o futuro de gerações posteriores.

É dentro dessa normativa de gerações futuras que cabe-se também a importância do solo quanto ao cunho social e econômico, visando o valor de importância equivalente adotado para a água. Para Magalhães et al (2021), isso se deve ao fato de que as produções, desde os primórdios das civilizações, sempre ocorreram nos solos e é sua capacidade de produção que permite a produção de alimentos que permitem a alimentação do ser humano.

É notável o quanto que a água e o solo estão interligados e quase que independente das proposições ou meios em que são discutidos. A análise socioeconômica permite com clareza mostrar que problemas como as relações do meio e democracia, a fome, a pobreza, a produção industrial e dentre outros estão intimamente ligados ao seu uso, quantidade e forma de utilização e obtenção (ZONTA, 2007).

Em se tratando dos dois últimos itens do parágrafo anterior (utilização e obtenção) é que abre-se a porta para a breve narrativa desse elemento (solo) quando avaliado do ponto de vista ambiental. Segundo Lima e Lima (2008), uma vez compreendido suas respectivas importâncias em torno dos cunhos sociais e econômicos, o viés ambiental serve como um alerta para as prerrogativas. 
O desenvolvimento humano acelerado das últimas décadas permitiu um crescimento nunca antes visto quando comparados com os séculos anteriores. Segundo Santos e Aquino (2016), boa parte desse desenvolvimento está atrelado ao desenvolvimento científico e como que tal desenvolvimento permitiria um uso ainda maior e mais específico tanto do solo.

No entanto, com o crescimento (que em maior parte ocorreu de modo desenfreado) veio problemas que acometeram principalmente o meio ambiente natural, quando analisados em sua totalidade como ecossistemas. Segundo Ribeiro e Rolim (2017), dentro dessa problemática surgiu a transcrição quanto ao que geraria esses resultados como o uso e ocupação de solo de forma desordenada, a utilização da água com pensamento de recurso infinito e sem controle, a poluição dos meios hídricos e dos solos, etc.

Dessa forma, o viés ambiental tanto da água como do solo em um cenário atual, permite estudos que norteiam a relevância em se cuidar do que ainda se tem, ou das quantidades ainda existentes. Muitos rios atualmente (em escala nacional ou mundial) estão em processo de poluição ou encontram-se poluídos (Almeida, 2019).

Boa parte dos solos que deveriam servir para habitat de espécies nativas de determinados ecossistemas encontram-se ou degradados ou ocupados de maneiras inapropriadas o que resulta em um desgaste gradual e contínuo do mesmo. O solo assim como a água possui um limite em torno do seu uso, e quando não utilizado ou manejado da maneira correta se degasta o que impede de voltar a um estado de produção inicial (Rodrigues, 2021).

O cuidado em torno das pesquisas que visam o cuidado do solo não são apenas importantes, são essenciais para o cenário atual. Para Ramos et al (2018), a população aumenta, o mundo precisa ser alimentado, mais porções de terras serão ocupadas e utilizadas para a produção de frutas, legumes verduras ou demais commodities. Compreender as formas corretas da utilização desses elementos não deverá ser apenas uma indicação, mas sim uma necessidade.

\subsection{As propriedades físicas do solo}

Para compreender o meio em que determinado estudo se dirige, independente de qual meio ele seja (água, ar ou terra), sempre tem-se a necessidade em compreender o seu comportamento, a sua atuação, as suas funcionalidades e como este solo se comporta em virtude de ações geradas pelo ambiente externo.

É dentro dessa busca pela compreensão do funcionamento que se faz necessário entender inicialmente quais são as propriedades que esse determinado meio possui, e como essas propriedades interferem, auxiliam ou reduzem determinadas funções que determinados tipos de solos possuem em certos ambientes.

Sendo assim, conforme Rosa (2010), a particularização em torno dessas propriedades é de suma importância, uma vez que são elas que especificam o tipo de solo bem como o seu comportamento a fatores externos. Essas propriedades merecem atenção por serem cruciais para a avaliação em torno da produtividade, estabilidade, crescimento das plantas e como indicadores de alterações no meio.

Afim de nortear a conceituação em torno das propriedades físicas do solo, entende-se que tais propriedades se referem à qualidade do solo quando relacionada aos processos de infiltração, de retenção, de disponibilização de água para as plantas e que, por sua vez, propicia as trocas de calor e de gases com a atmosfera e as raízes das plantas e possibilitando o crescimento das raízes dentro outros (Neves ET AL, 2007).

Entre as propriedades físicas a serem discutidas incluem-se a textura, estrutura, porosidade, a densidade, a agregação do solo e o tamanho das partículas. Cada uma dessas propriedades apresentadas possui relação direta ou indireta com a forma como este solo se comporta, seja para fins de produção econômica ou como resposta a uma determinada ação que foi realizada naquele meio (MellonI, 2008). 
A textura do solo está relacionada à sensação ao toque de uma determinada porção de solo quando levada ou esfregada na mão. Para Niero et al (2010), a fundamentação de tal processo se dá exclusivamente pela via tátil cabendo ao profissional a experiência quanto ao que pode ser realizado e ao dado obtido.

A textura do solo é responsável pelo processo de descrição em torno do tamanho das partículas que compõem o solo. As partículas minerais mais grosseiras são normalmente incorporadas, e cobertas, por argila e outros materiais coloidais. Por sua vez, as partículas coloidais são as que são muito pequenas tornando-as invisíveis a olho nu, enquanto que as não coloidais são as partículas maiores e possuem como particularidade o fato de não possuírem cargas elétricas (Brun, 2008).

A textura do solo refere-se distribuição do tamanho das partículas minerais do solo, sendo classificadas em três frações, areia, silte e argila. A textura constitui-se numa das características físicas do solo mais estáveis, apresentando grande importância tanto na identificação e classificação, quanto na predição do seu comportamento (Van Lier, 2010). Interfere em diversas características do solo como retenção de água, velocidade de decomposição da matéria orgânica, capacidade de lixiviação, suscetibilidade a erosão hídrica e eólica, compactação, capacidade de troca catiônica (CTC), grau de agregação das partículas, além de influenciar atributos físicos como densidade do solo e porosidade (Brady; Weil, 2008).

Além disso, conforme a Cetesb (2021), a textura de um solo não é prontamente sujeita a mudanças, por isso é considerada uma propriedade básica do solo. Seguindo a linha de conceituação e identificação dessas propriedades, a estrutura pode ser entendida como uma propriedade que realiza a avaliação em torno do arranjo entre o espaço vazio e os sólidos ali existentes.

Entende-se por estrutura o arranjo das partículas do solo e do espaço poroso entre elas (Marshall 1962). As frações minerais e orgânicas se unem através de processos físicos, químicos e biológicos formando os agregados, considerados unidades básicas na organização estrutural do solo. A estrutura do solo exerce influência direta sobre movimentação de água, transferência de calor, aeração, densidade do solo e porosidade (Letey, 1985), e pode ser alterada pelas práticas de manejo do solo e dos cultivos agrícolas (Tormena et al., 1998; Pires et al, 2008).

Para Rosa (2010), a importância da estrutura como propriedade do solo se refere à sua influência sobre o crescimento das plantas, pois essa propriedade influencia a capacidade de infiltração da água, a forma como o processo de aeração ocorre e consequentemente a penetração das raízes das plantas nesse solo.

A porosidade do solo é a fração volumétrica ocupada com ar e/ou água, sendo o espaço onde ocorrem os processos dinâmicos do ar e da solução no solo (Hillel, 1970). Além disso, a distribuição do espaço poroso do solo condiciona o seu comportamento físico-hídrico (Klein; Libardi, 2002).

Segundo Santos (2021), a porosidade do solo é uma propriedade que está relacionada diretamente aos processos de retenção e condução da água, no processo de aeração na forma como o processo de penetração das raízes pode ocorrer e consequentemente como determinados nutrientes poderão ser disponibilizados para o consumo pelas plantas.

Por sua vez, a densidade é propriedade que permite a avaliação em torno da relação entre a massa e o volume de um determinado solo, ou seja, realiza a descrição quanto ao estado em que a estrutura do solo se encontra. Conforme a Embrapa (2018), um ponto importante é que a densidade está também associada a profundidade em que determinada porção é avaliada, seja mais superficialmente ou mais internamente, além disso, se relaciona com o meio em análise, possuindo valores diferentes para ambientes diferentes (pastagens, florestas, mangues, etc.).

Conforme Neves et al (2007), a agregação do solo está relacionada a forma como um determinado solo é manejado e assim, como este solo se apresenta por meio desse manejo. A correlação é com o carbono e com a matéria orgânica que existe naquele meio, ou seja, as relações existentes entre o solo e a disponibilidade de matéria orgânica que permite a sua estabilização e formação. 
O tamanho dos agregados, como parâmetro final de análise (isso em relação aos que já foram mencionados) se apresenta como uma propriedade que está relacionada ao crescimento das plantas. Para Niero et al (2010), esse é um parâmetro de crucial importância pois, por meio de sua análise, se permite avaliar a estrutura de um determinado solo bem como a resistência que os agregados possuem.

Conforme a Cetesb (2021), um ponto importante sobre essas propriedades é que elas são responsáveis pelos mecanismos de atenuação física quanto aos poluentes, como filtração e lixiviação, possibilitando ainda condições para que os processos de atenuação química e biológica possam acontecer.

\subsection{A degradação do solo em um contexto atual}

Como já mencionado em tópicos anteriores e ainda na introdução do trabalho, o mundo passa um período em que mais e mais tecnologias surgem para que haja uma forma de suprir as necessidades humanas principalmente em torno do conforto, segurança e estabilidade. Essas tecnologias também servem para propiciar de forma exponencial um ganho substancial quanto à produção de alimentos ao redor do mundo.

Atrelado a esse avanço de produção, está o crescimento urbano de áreas que antes não sofreram ou não sofriam de maneira diretas por ações humanas bem como os recursos que, por sua vez, passam a ser utilizados. Para Ribeiro e Rolim (2017), é dentro desse paradigma que surge a discussão: O problema não está em usar o recurso, mas na forma como este é utilizado e consumido.

Para Rosa (2010), diferentemente da água, o solo, quando mencionado aqui um solo propício para agricultura, demora milhares de anos para a sua formação, ou seja, fora da ordem ou padrão cronológico do tempo de vida de um ser humano, assim como de oito ou mais gerações futuras, dependendo do tipo de solo e da rocha-mãe de formação.

Conforme Ramos et al (2018), isso significa que quando não tratado de forma correta, quando acometido de ações que prejudiquem, degradem ou minimizem as suas funções de recuperação ou ainda não aplicado formas de restauração ou reabilitação adequadas, esse solo pode perder a sua capacidade de produção, tornando-se um solo infértil ou ainda passível da não sujeição ao processo urbanístico.

Segundo Castro (2021), seja de uma forma ou de outra, o ser humano bem como o ecossistema que ao qual esse solo abrigava são diretamente impactados pelos processos degradatórios que antes ocorreram ali, impossibilitando a vida, o progresso e o próprio desenvolvimento do ecossistema que havia ali de inúmeras formas diferentes.

Seja por meio de processos erosivos (que podem ou não serem atenuados por ações humanas) ou pela compactação do local, ambos influenciam na capacidade do solo para reter água e fornecer oxigénio às raízes das plantas. Quando baixa a capacidade de retenção de água do solo, os rendimentos diminuem, o escoamento de água aumenta e o solo torna-se mais vulnerável à erosão por meio do processo de compactação (Magalhães, 2021).

A perda de nutrientes, a capacidade de retenção da água, aumento da fração grossa e dentre outros, são sinais que podem ser claramente visualizados a analisados afim de que uma iniciativa seja tomada para a restauração do local. Segundo Rosa (2010) o que não se pode é deixar um local que claramente não possui a capacidade de retornar ao seu estado natural por conta própria, pois tal ato pode agravar o processo de reabilitação da área.

Atrelado a isso, Ramos et al (2018), aponta que há um descaso quase que social quanto ao fato de ver-se que algo está acontecendo, mas ser incapaz de tomar uma mínima iniciativa quanto ao ocorrido, deixando apenas "do jeito que está". São omissões desse tipo, atrelada a intensidade de ações humanas como queimadas, desmatamentos, despejo de resíduos tóxicos, dentre outros, que confere a corpos hídricos o título de poluído ou com incapacidade para abastecimento humano.

Conforme Martins (2021), existe uma clara necessidade de mudança de pensamento quanto ao recurso que se pretende utilizar e forma ou quantidade que deve-se utilizar, pois assim como um ser humano, tal recurso necessita de nutrientes, de 
cuidados, de atenção, de zelo e monitoramento, pois assim como as demais coisas existentes no mundo, quando não tratadas de forma coerente, tornam-se impróprias ou deixam de existir.

\subsection{Técnicas de reabilitação/recuperação do solo}

Conforme IGA (2021), são inúmeros os processos que podem comprometer a estrutura física, química e biológica de um determinado solo, geralmente, associadas a ações antrópicas que desregularam os processos naturais que ali deveriam ocorrer ou que ainda impossibilitam o processo de recuperação natural deste solo.

Uma vez que é percebido o problema, em um contexto mais atual, o que percebe-se é que muitos destes solos são abandonados, pois, para a visão humana, deixaram de ter a sua utilidade quanto aos processo de produção. No entanto, para Morgan (2005), o que ocorre é que em muitos casos, o solo foi tão degradado que perdeu a sua capacidade de recuperação por processos naturais, o que acarreta problemas sérios como erosão, surgimento de voçorocas e processos de desertificação.

É visando impedir que esse tipo de problema comprometa os solos de determinados ambientes que práticas podem ser utilizadas visando-se o processo de restauração, ou de máxima recuperação do local e área que foi comprometido (LEPSCH, 2011). No entanto, para que isso ocorra, uma série de fatores devem ser levados em consideração, afim de que haja um embasamento mais verídico quanto ao estado de um determinado solo.

A primeira etapa deste processo de avaliação, consiste em entender as propriedades desse solo e em qual estado ele se encontra com o intuito de se orientar quanto à aplicação da melhor técnica que deverá ser utilizada. Para Tominaga (2007), é por essa razão que o estudo das propriedades citadas no tópico 2.6 (propriedades físicas do solo) do presente trabalho são tão importantes, pois elas levam ao norteamento quanto ao estado atual do solo em estudo.

Juntamente a isso, deve-se levar em consideração também uma análise criteriosa dos parâmetros químicos e biológicos, pois eles também ajudarão a compreender as características que definem o estado em que um determinado solo se encontra. Além disso, para IGA (2021), também é possível, como parte da avaliação, se utilizar do levantamento visual quanto à identificação de espécies no ambiente que indicam a degradação do solo como, por exemplo, a barra de bode, capim rabo-deburro, caraguatá, etc.

De acordo com Primavesi (2008), o conjunto desse levantamento de dados e informações irão classificar o solo, e assim, permitir a aplicação de práticas de recuperação/reabilitação que são mais condizentes com o seu estado. No geral, as práticas aqui apresentadas trabalham em conjunto pois é a sua totalidade aplicada ao ambiente que irão lhe conferir maiores e melhores resultados ao solo e sua estrutura.

De acordo com Wadt (2004), entre as técnicas para a recuperação e reabilitação do solo, tem-se: as técnicas vegetativas, técnicas edáficas e técnicas mecânicas. Cada uma dessas técnicas possui características que são condizentes com à forma em que o solo se encontra. Ou seja, o ideal é que haja uma integração entre essas três técnicas apresentadas para que de fato ocorra uma melhoria do solo.

As técnicas vegetativas, como condicionante à sua própria descrição, se utilizam das mais variadas espécies de plantas para o processo de recuperação do solo. Segundo a Embrapa (2008), ela se utiliza de plantas que são resistentes à condições extremas (quanto ao processo de recuperação do solo, que suportam a baixa disponibilidade de água no ambiente e que ainda consigam sobreviver em solos pobres em nutrientes.

De acordo com Andrade, Portocarrero e Capeche (2005), entre as plantas utilizadas nesse processo de recuperação pela técnica vegetativa, pode-se citar a classe das gramíneas, conhecidas por seu alto sistema radicular e pertinentes a processos erosivos e as leguminosas que são importantes para a produção de biomassa e são boas na fixação de nitrogênio.

Por sua vez, as técnicas edáficas visam manter ou melhorar a estrutura e qualidade do solo por meio de técnicas como: a calagem, gessagem, adubação, rotação de culturas e o plantio direto na palha. Para Pereira et al (2015), essa capacidade do solo 
apresentada se constitui em sua capacidade que o mesmo possui em desempenhar funções essenciais para o homem e o próprio ambiente.

De forma simplificada, a calagem é o processo em que se adiciona cálcio e magnésio para as plantas e atua nas primeiras camadas do solo alterando o pH, e fornecendo Ca e Mg. Já a gessagem, segundo Lepsch (2011), atua nas camadas mais profundas e é responsável por diminuir de forma considerável a toxidade do alumínio, além disso, fornece cálcio e enxofre e ainda atua como um "condicionador" pois fornece uma estrutura que não altera as cargas $\left(\mathrm{OH}^{-}\right.$e $\left.\mathrm{HCO} 3\right)$, sendo o $\mathrm{OH}^{-}$responsável por atrair as cargas positivas que elevam o $\mathrm{pH}$ do solo.

A adubação do solo é um processo que atua na regeneração do solo e consiste em aumentar a disponibilidade nutrientes para o crescimento das plantas (NPK). Conforme Primavesi (2008), esse processo de adubação pode-se dá de duas formas: Mineral- utiliza-se de um adubo inorgânico para o processo, e esse adubo é construído por meio do processo de extração do refino do petróleo em bases fosfatadas e nitrogenadas; Orgânica- se utiliza de restos de folhas para realização do processo de inserção de nutrientes ao solo.

Segundo Andrade, Portocarrero e Capeche (2005), a consorciação de culturas é um processo que se utiliza de diferentes tipos de cobertura, otimizando o regime de fertilização e controlando as ervas daninhas no ambiente. Nesse tipo de metodologia é essencial se definir a cultura principal e a planta consorciada, bem como conhecer cada uma das plantas que serão colocadas naquele meio.

Segundo Almeida (2019), no caso das técnicas mecânicas, são técnicas que visam reduzir ou parar o processo de degradação e é voltada para a mecânica processual erosiva. Entre algumas dessas técnicas estão o terraceamento, o cultivo em nível e os canais escoadouros.

Conforme a Embrapa (2008), o terraceamento é um método mecânico de conservação do solo que consiste na construção de um canal em um camealhão dispostos transversalmente ao plano declivo, tendo-se um máximo cuidado com o dimensionamento para este tipo de método. Já o cultivo em nível consiste em marcar pontos de mesma cota no sentido perpendicular à declividade, desenhando curvas no terreno da mesma altitude.

$\mathrm{O}$ trato em torno da boa recuperação de um solo, de um ponto de vista mais generalizado, consiste no processo de avaliação desse solo e do que ele precisa para se recuperar. Segundo Tominaga (2007), é importante frisar que nem todo solo possuirá a capacidade de retornar ao seu estado natural por conta própria, principalmente aqueles que foram demasiadamente degradados.

Sendo assim, segundo Pereira et al (2015), a utilização das técnicas apresentadas, trabalhadas em conjunto, apresentam uma forma de recuperar ou reabilitar esse solo, tentando sempre que possível o deixá-lo mais próximo das suas características naturais e assim torna-lo novamente apto ao ambiente em que está inserido.

\section{Metodologia}

\section{1 Área de estudo}

A cidade de Balsas-MA (Figura 1), recebe esse nome devido ao Rio das Balsas. O Rio das Balsas é um dos maiores afluentes da Bacia do Rio Paranaíba em termos de volume de água, sendo seu estudo bastante importante para a gestão e manutenção deste recurso. A área de estudo faz parte da área delimitada pelo Instituto Brasileiro de Geografia e Estatística (IBGE) chamada de Unidade de Negócios de Balsas localiza-se na região centro sul do Estado é composto 28 municípios, compreendendo uma área de 85.114,02 mil Km². Ainda de acordo com o Censo Demográfico de 2010, a área de abrangência da Unidade de Negócios possui uma população de 448,1 mil pessoas, com 64,4\% localizada na zona urbana.

No período de 2000-2010 apresentou uma taxa de crescimento anual da população de 1,2\% e enfatizando que não foi inserido as informações mais recentes pois não houve um levantamento do IBGE para o ano de 2020, apenas previsões (IBGE, 
2010).

Figura 1: Mapa de Localização da área de estudo.
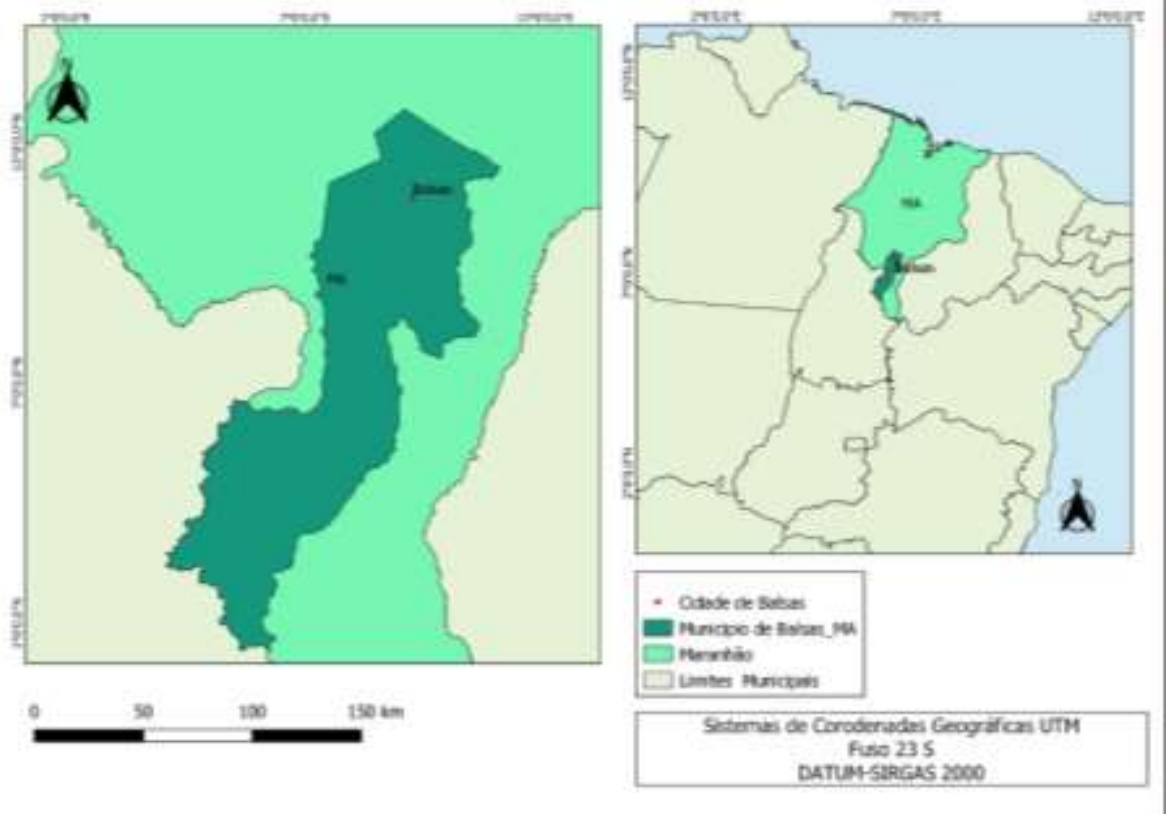

Fonte: Autores (2021).

A região apresenta um clima quente e úmido e vegetação típica do cerrado propício para agricultura e a pecuária. Já o município de Balsas possui 83.537 habitantes, área de 13.141,733 Km² e densidade demográfica de 16,36 hab/Km². Conforme o levantamento exploratório realizado pela Embrapa (2017), as principais classes encontradas nessa região são: Latossolo Amarelo, Neossolos Nitólicos e os Plintossolos. Do total da população residente, cerca de 49,8\% (41.574 pessoas) é do sexo masculino e $50,2 \%$ (41.954 pessoas) do sexo feminino, 76,6\% (63.958 pessoas) são alfabetizadas e $87,1 \%$ (72.771 pessoas) reside na área urbana (IBGE, 2010).

Figura 2: Mapa de localização da área de estudo que se encontra às margens do rio Balsas e nas proximidades do bairro Trizidela.

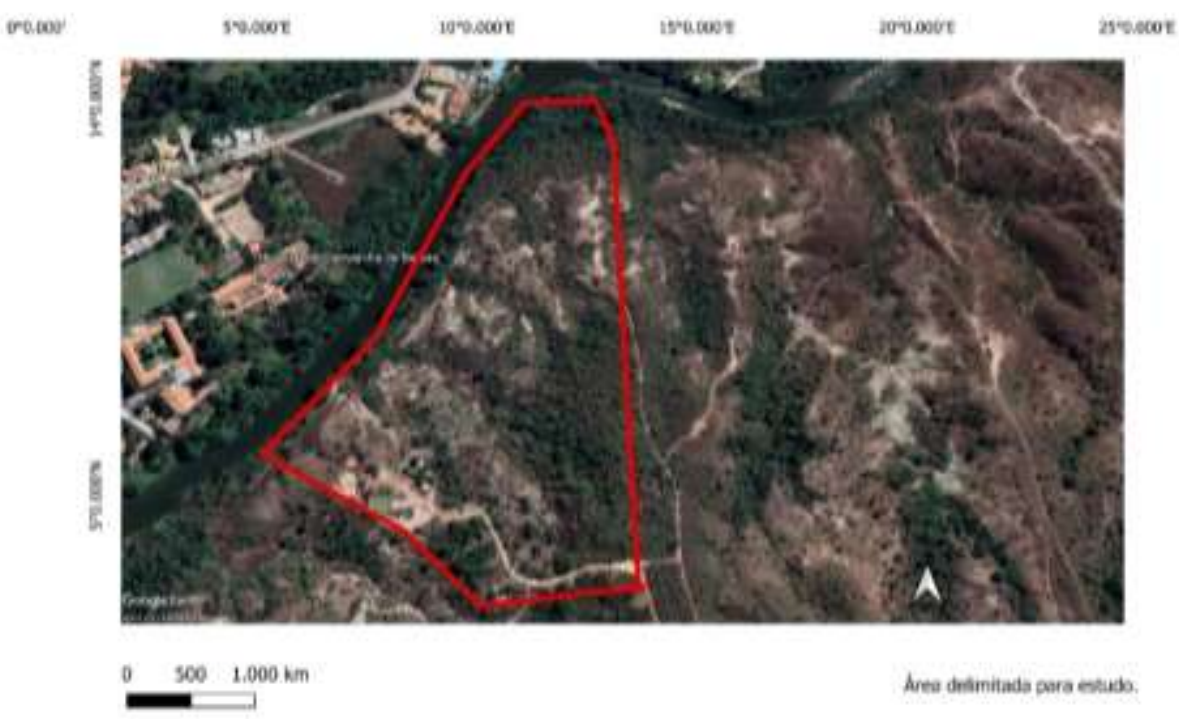

Fonte: Autores (2021). 
A presente área delimitada para estudo se localiza às margens do rio Balsas e nas proximidades do Bairro Trizidela e possui por delimitação (como mostrado na Figura 2 acima) as estradas que dão acesso a outros demais povoados ou outras propriedades que ficam próximas ao perímetro urbano do município.

A área de estudo apresenta um histórico de degradação e ocupação desordenada (Figura 3a). De acordo com o que foi relatado pelos moradores próximos ao local, com frequência são realizadas queimadas sem o intuito de fazer plantios ou outras atividades produtivas. Quando as queimadas não são propositais, focos de incêndios vindos de outras áreas acabam também chegando ao local, colocando em risco inclusive a vida dos moradores.

Outro problema percebido na área é que constantemente a vegetação remanescente é cortada principalmente por pessoas que querem ter acesso à margem do rio para atividades de lazer, como banho de rio, pesca e caça (Figura 3b). Infelizmente, além do corte da vegetação, essas pessoas acabam deixando também lixo não orgânico e restos de comida no local.

A mata ciliar apresenta-se totalmente fragmentada, com alguns resquícios de vegetação e outros locais com aspecto de degradação severa. Devido à ausência de vegetação próximo à margem do rio onde o estudo foi realizado, quando o nível se eleva, no período chuvoso, acaba provocando erosão nas margens do rio, causando o aparecimento de voçorocas no local (Figura $3 c)$.

Nas áreas mais distantes da margem do rio também há a presença de erosão do solo em estágio avançado. Neste caso, se dá principalmente devido a retirada da vegetação e ao relevo íngreme do local (Figura 3d).

Figura 3: Localidade dentro de Balsas-Ma às margens do rio Balsas e nas proximidades do bairro Trizidela.
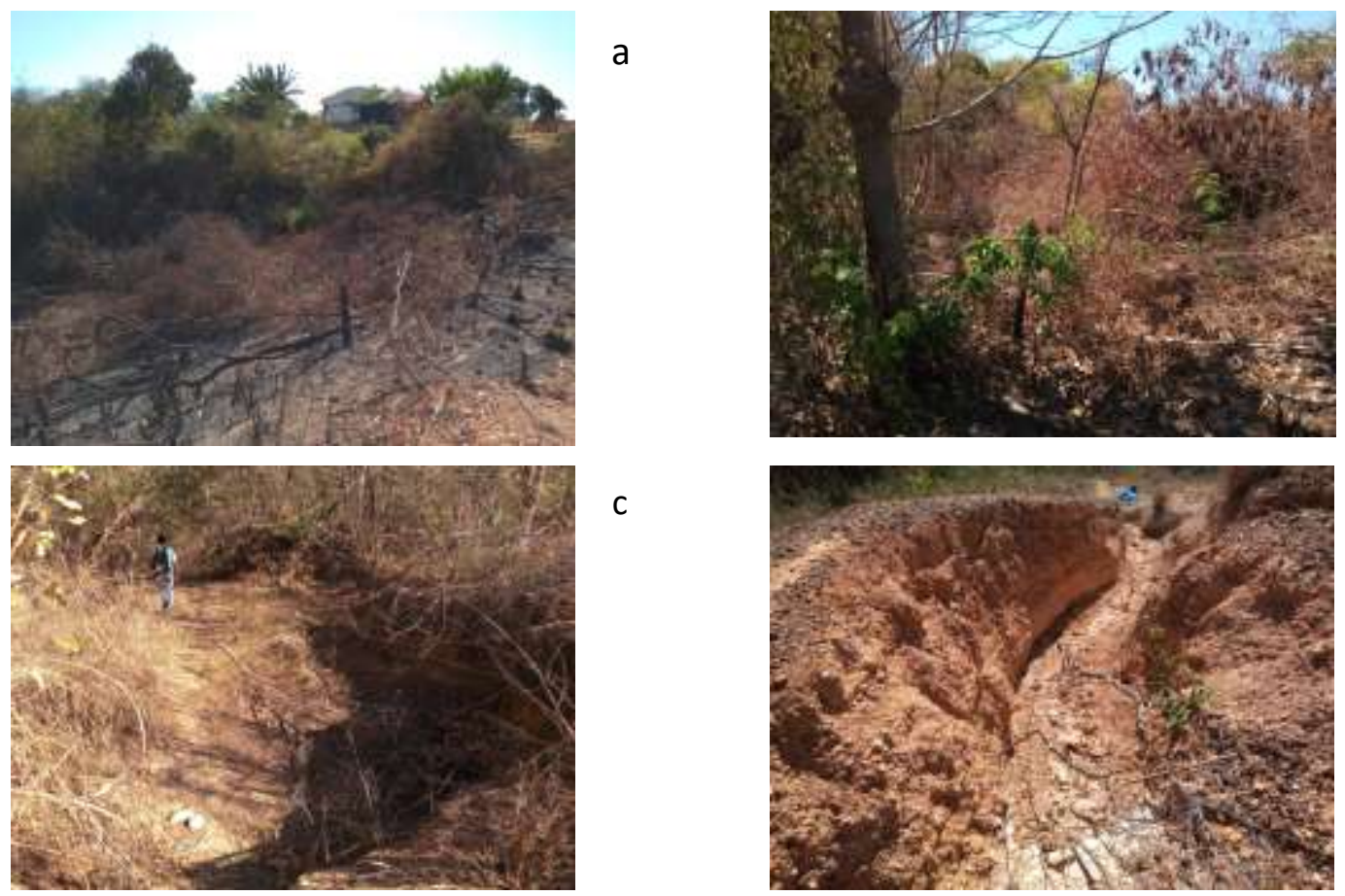

d

Fonte: Autores (2021).

Utilizando-se de um GPS (Global Positioning System, que significa “Sistema de Posicionamento Global”), realizou-se a marcação dos pontos/locais onde seriam realizadas as coletas para amostragem do solo. Cada um dos locais foi escolhido afim de entender ou compreender melhor as principais propriedades e características presentes daquela área. Os pontos e suas respectivas marcações geográficas estão presentes no Quadro 1 a seguir. 
Quadro 1: Coordenadas geográficas dos pontos de amostragem nas proximidades do bairro Trizidela e ás margens do rio Balsas.

\begin{tabular}{|c|c|c|}
\hline Local de amostragem & $\begin{array}{l}\text { Dia da realização da coleta das } \\
\text { amostras }\end{array}$ & Coordenadas geográficas \\
\hline Ponto 1 & $14 / 07 / 2021$ & $\begin{array}{l}\text { S 07³1'57.1'”} \\
\text { W } 046^{\circ} 01^{\prime} 48.5^{\prime \prime}\end{array}$ \\
\hline Ponto 2 & $14 / 07 / 2021$ & $\begin{array}{l}\text { S } 07^{\circ} 31^{\prime} 58.4^{\prime \prime} \\
\text { W } 046^{\circ} 01^{\prime} 48.3^{\prime \prime}\end{array}$ \\
\hline Ponto 3 & $14 / 07 / 2021$ & $\begin{array}{l}\text { S } 07^{\circ} 31^{\prime} 01.3^{\prime \prime} \\
\text { W } 046^{\circ} 02^{\prime} 18.6^{\prime \prime}\end{array}$ \\
\hline
\end{tabular}

Fonte: Autores (2021).

Figura 4: Área delimitada para estudo com os pontos em que as amostras foram coletadas.

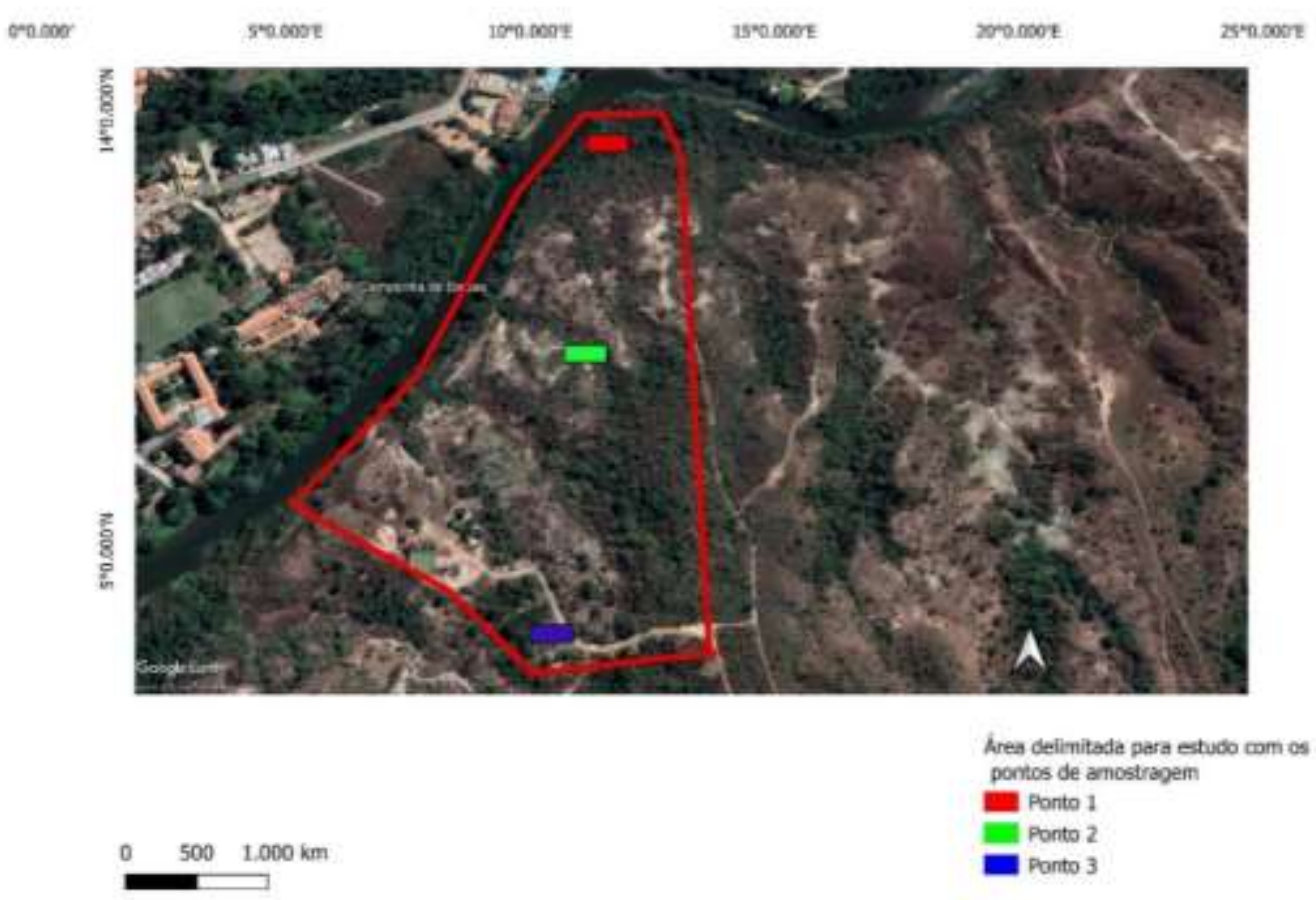

Fonte: Autores (2021).

Utilizou-se do programa Google Earth, para centralização dos pontos de georreferencia juntamente com o programa Qgis para a criação das imagens de delimitação e posterior averiguação dos pontos amostrais que foram realizados. O programa QGis é um software livre com código-fonte aberto, e conforme a Figura 5, é possível observar que os pontos foram verificados em conformidade quanto ao distanciamento do rio, ou seja, um ponto à beira-rio, outro mais distante (intermediário), e outro bem mais afastado do rio.

O ponto 1 (Figura 5) foi escolhido em uma área próxima ao rio Balsas. A área da estava ainda com vegetação densa e típica da região. No solo em si, havia uma camada considerável de serrapilheira e indícios de presença e atividade de macro, e microrganismos e grande de diversidade de raízes, devido a aparente preservação do local. 
Figura 5: Ponto de coleta 1-Ponto de amostragem mais próximo ao rio.

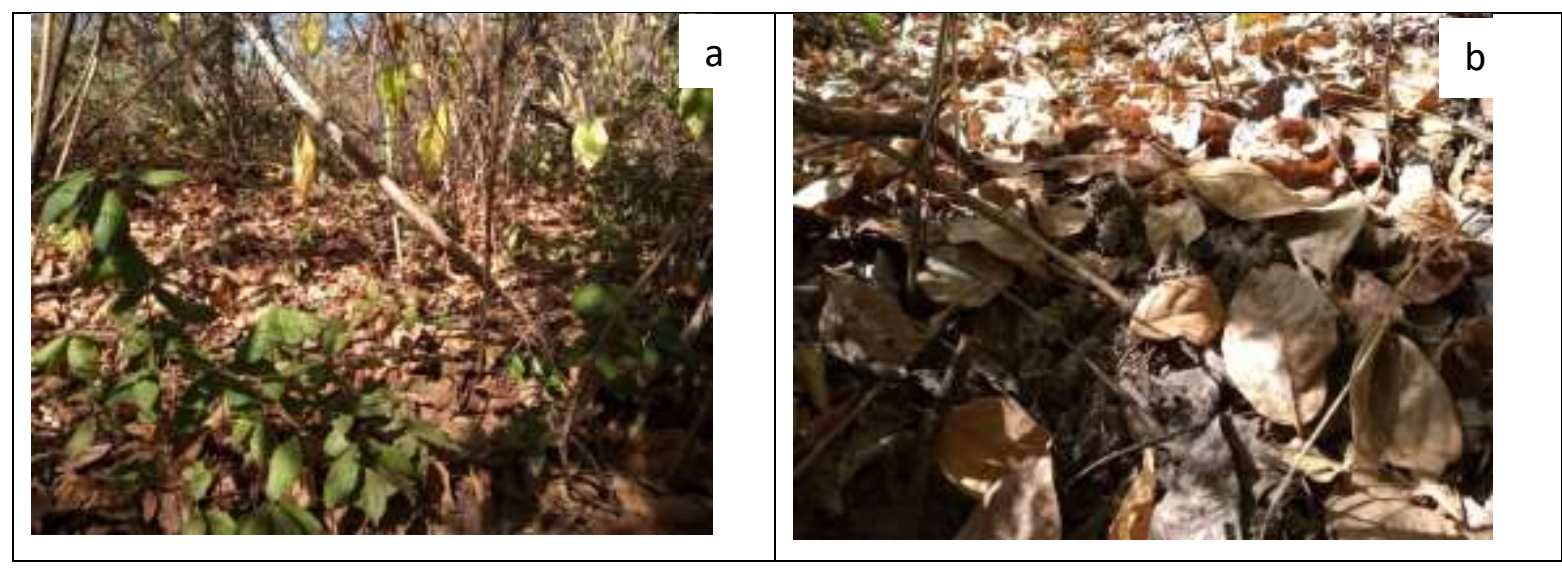

Fonte: Autores (2021).

O ponto 2 (Figura 6) localiza-se na região intermediária no terreno, a vegetação local apresentava características de vegetação primária e secundária, como gramíneas e arbustos de pequeno e médio porte, indicando a atuação processo natural de sucessão ecológica que ocorre após a degradação sofrida por uma área (Figura 6a). Além disso, a vegetação apresentava aspecto seco (devido a amostragem ter sido realizada no período seco do ano) e retorcida, com nenhuma ou pouca presença de camada de serrapilheira sobre o solo.

O solo apresentava poucos sinais de atuação de organismos e raízes escassas e achatadas. Havia presença de pedras e afloramentos com fragmentos de rocha sobre o solo, indicando a lavagem da superfície do solo pela água da chuva e consequente erosão laminar (Figura 6b). Na área também era visível a presença de lixo, inclusive em camadas mais profundas do solo.

Figura 6: Ponto de coleta 2-Ponto intermediário entre os pontos 1 e 3 de relevo mais plano.

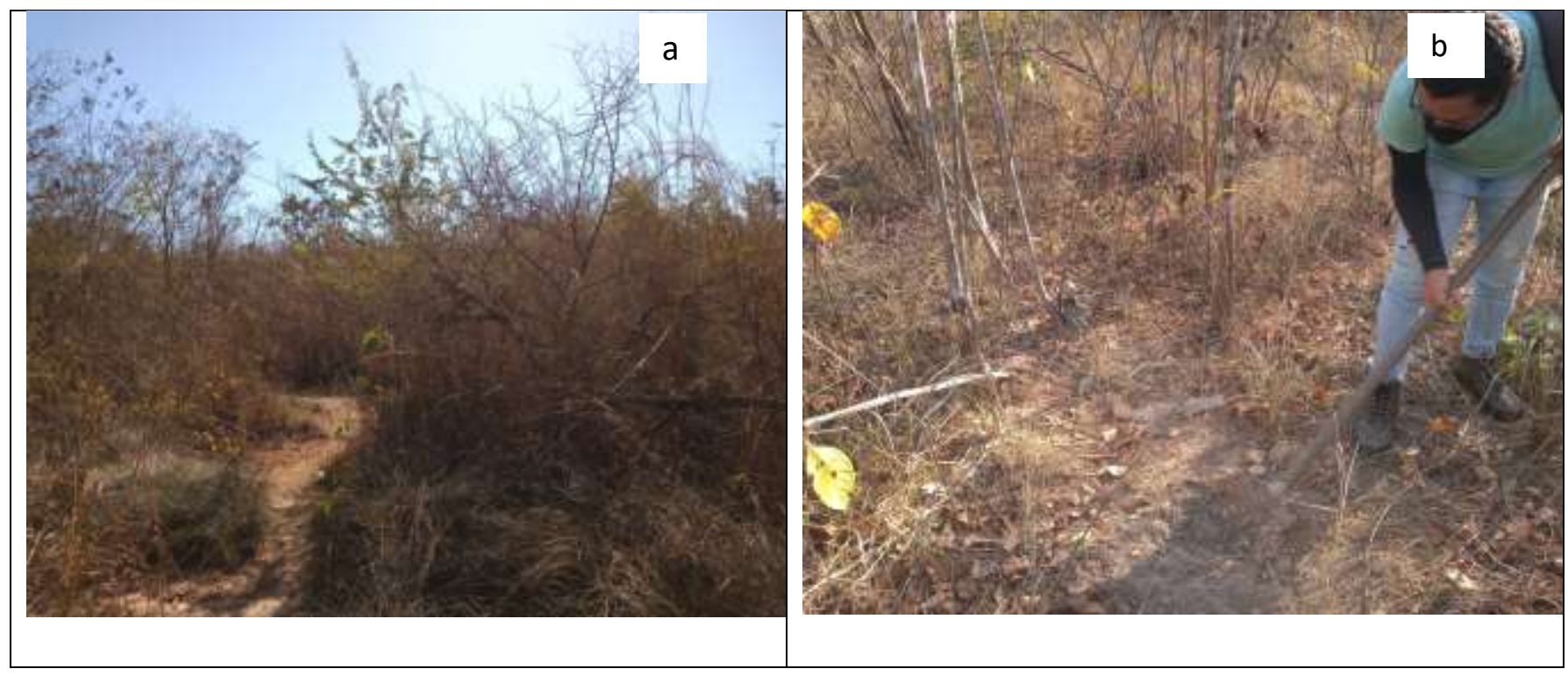

Fonte: Autores (2021).

O terceiro ponto de coleta localiza-se na parte mais elevada no terreno (Figura 7). Esse local encontra-se totalmente sem vegetação, com degradação do solo em nível severo (Figura 7a). Boa parte da superfície do solo já foi levada pela erosão, sendo que em muitos locais já é possível observar a camada rochosa do solo próximo à superfície. As plantas que ainda resistem no local estão com suas raízes descobertas e com risco de tombamento. Há presença de voçorocas em vários locais e com risco de 
abertura de mais crateras no solo (Figura 7 b e c). No solo não foi percebido indício de atuação de organismos e as raízes são praticamente ausentes.

Figura 7: Ponto de coleta 3-Ponto mais distante do rio.
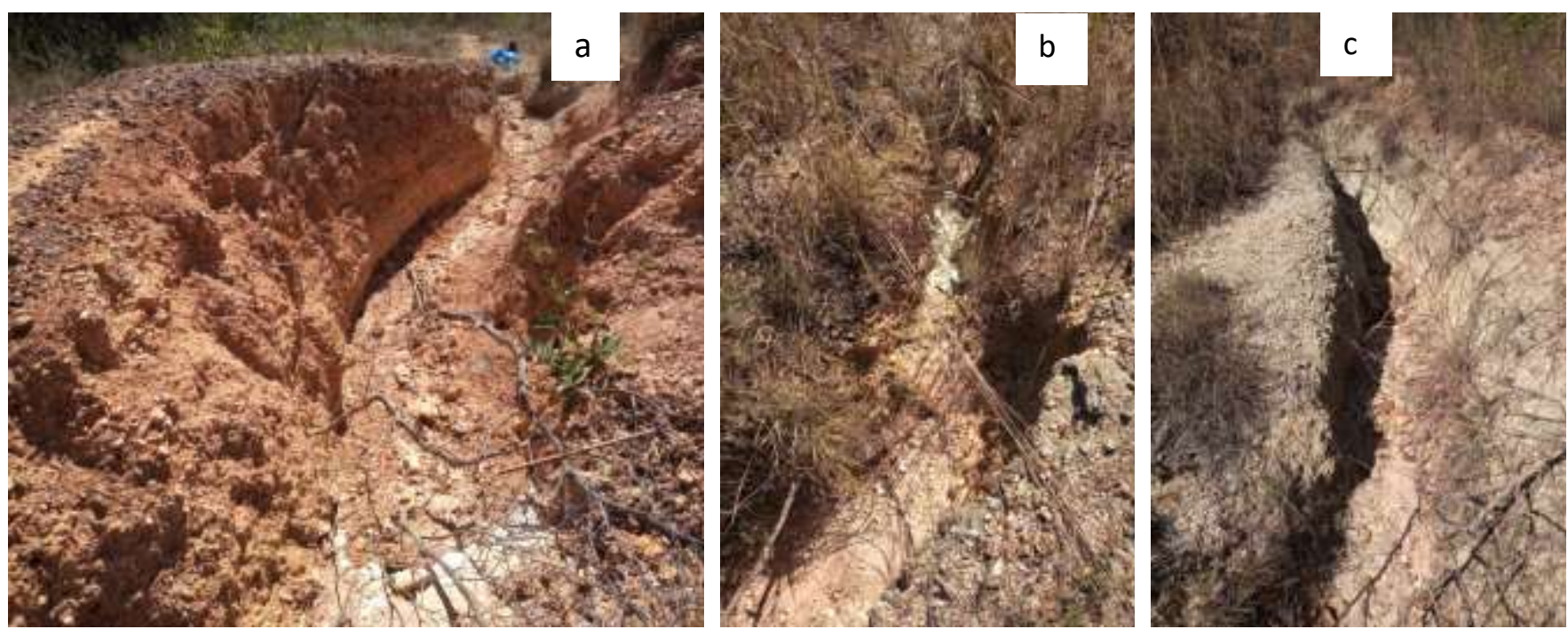

Fonte: Autores (2021).

\subsection{Procedimentos Metodológicos}

Os locais de amostragem de solo dentro da área delimitada para o estudo foram selecionados de forma que os resultados sejam representativos da maior parte da área de estudo.

Foram coletadas amostras de solo com estrutura indeformada e deformada (com estrutura do solo preservada e não preservada, respectivamente) da camada superficial do solo $(0-10 \mathrm{~cm})$ e na camada subsequente $(10-20 \mathrm{~cm})$ para realização das análises físicas e estruturais do solo.

Como já descrito anteriormente foram escolhidos três pontos para coleta das amostras, um à beira-rio, outro mais distante da margem do rio (intermediário), e um terceiro ponto mais distante, buscando ter-se uma noção mais abrangente do solo do local em estudo.

Afim de criar-se um roteiro para a forma em que o trabalho foi realizado, primeiro será explicado os métodos em torno da obtenção das amostras em campo para somente depois a compreensão quanto à metodologia utilizada para a identificação dos demais parâmetros em laboratório.

\subsubsection{Propriedades físico-estruturais, teor de matéria orgânica e carbono orgânico do solo}

As propriedades físico-estruturais estudadas neste trabalho serão: textura do solo, densidade dos sólidos, densidade do solo, também será aqui apresentado a forma de obtenção do teor de matéria orgânica bem como também o diagnóstico rápido da estrutura do solo. A partir dos dados de densidade do solo e densidade dos sólidos será possível calcular a porosidade do solo. Além disso, será determinado também o teor de carbono orgânico do solo.

\section{- Textura do solo}

O processo de coleta do solo envolve uma série de etapas que consiste inicialmente de uma pequena limpeza superficial do local em que será coletada a amostra (Figura 8). Uma vez coletada as amostras de solo deformadas nas camadas delimitadas, 
elas foram levadas ao laboratório dentro de sacos plásticos e cada saco continha uma breve descrição quanto ao ponto em que foi coletada e sua respectiva profundidade, por exemplo: Ponto 1- 0-10 cm, a última parte $(0-10 \mathrm{~cm})$ corresponde a profundidade da camada. Uma vez identificadas, as amostras foram levadas para o laboratório de Geotecnia e Recursos Hídricos da UFMA, campus Balsas-MA, onde foram secas ao ar, destorroadas e peneiradas em peneiras de malha de 2,00 $\mathrm{mm}$ de abertura.

Ainda dentro dessa descrição é importante destacar que o processo de análise da textura do solo em estudo foi realizado pela empresa do município de Balsas conhecida como Terra Brasileira-Laboratório Agronômico, uma vez que não teve-se como realizar esse análise no laboratório do campus da UFMA. Ainda assim, o presente discente responsável pelo trabalho, realizou o seu estágio obrigatório I, nesta empresa, e com isso, foi possível explicar como se dá processo para obtenção desse dado. A análise granulométrica do solo na Terra Brasileira é feita pelo método do densímetro (GROSSMAN; REINSCH, 2002).

Figura 8: Processo de limpeza inicial para retirada das amostras de solo.

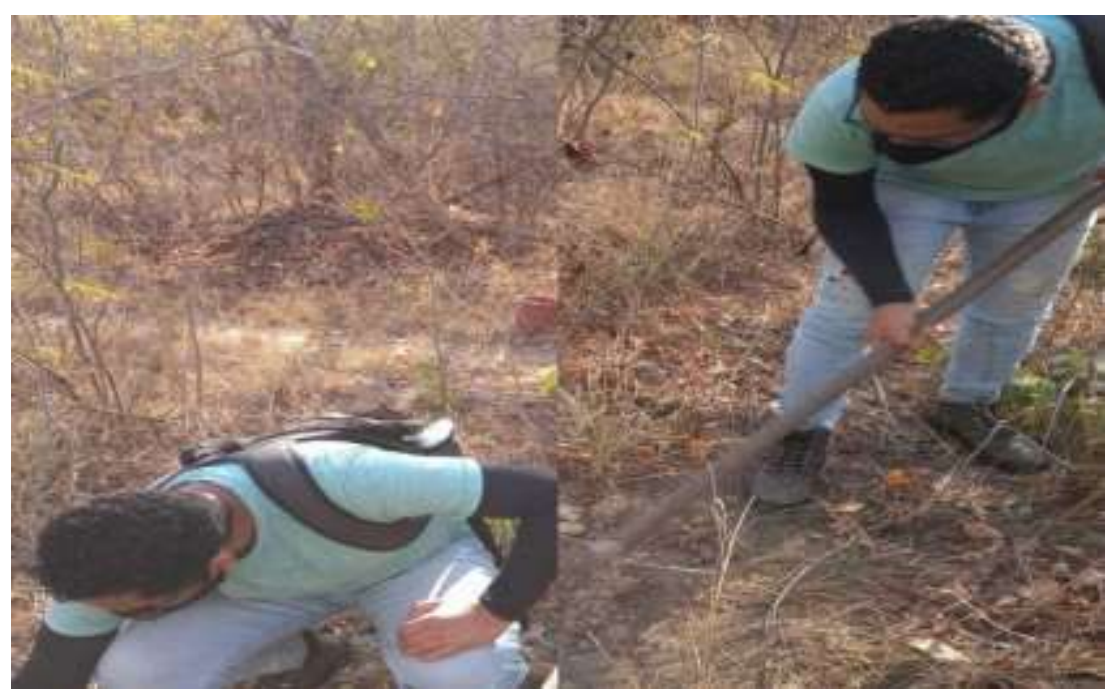

Fonte: Autores (2021).

\section{- Densidade dos sólidos ou das partículas ( $\rho s)$}

Densidade dos sólidos ( $\rho s$ ) do solo foi determinada pelo método do balão volumétrico (EMBRAPA, 2017): foram utilizados $20 \mathrm{~g}$ de TFSA que passou 72 horas em estufa de circulação de ar forçado, para garantir que a água higroscópica da amostra fosse eliminada (Figura 9a);

Assim que as amostras eram retiradas da estufa de circulação de ar forçado, elas foram imediatamente colocadas no dessecador para não deixar que a amostra entre em contato direto com a umidade do ar e assim evitando-se que ocorre-se possíveis erros na medida da massa seca (Figura 9b);

Após esse período, a massa de solo foi pesada, obtendo-se a massa de sólidos seco $\left(M_{S}\right)$, é sempre importante frisar que para saber o real valor de $M s$, o recipiente em que a amostra estava foi pesado anteriormente e o valor de $M s$ foi a diferença entre o peso do recipiente com a amostra menos o peso do recipiente vazio (Figura 9c);

Para se conhecer o volume ocupados pelos sólidos do solo, transferiu-se as $20 \mathrm{~g}$ solo, cuja a água foi eliminada pelo processo de secagem na estufa, para um balão volumétrico de $50 \mathrm{ml}$; Com auxílio de uma bureta graduada, adicionou-se, ao poucos, álcool etílico agitando sempre o balão para garantir que todo ar entre as partículas fosse totalmente eliminado, até atingir a marcação no balão correspondente ao volume deste (Figura 9d); Ao final, obteve-se o volume ocupado pelos sólidos do solo pela diferença do volume do balão sem os sólidos $(50 \mathrm{ml})$ e o volume de álcool adicionado até preencher todo o volume do balão 
com os sólidos dentro do balão, enfatizando que esse procedimento é realizado por meio da leitura da bureta por aferição do volume do balão volumétrico (Figura 9e).

Figura 9: Processo de obtenção dos dados da densidade das partículas ( $\rho$ ).

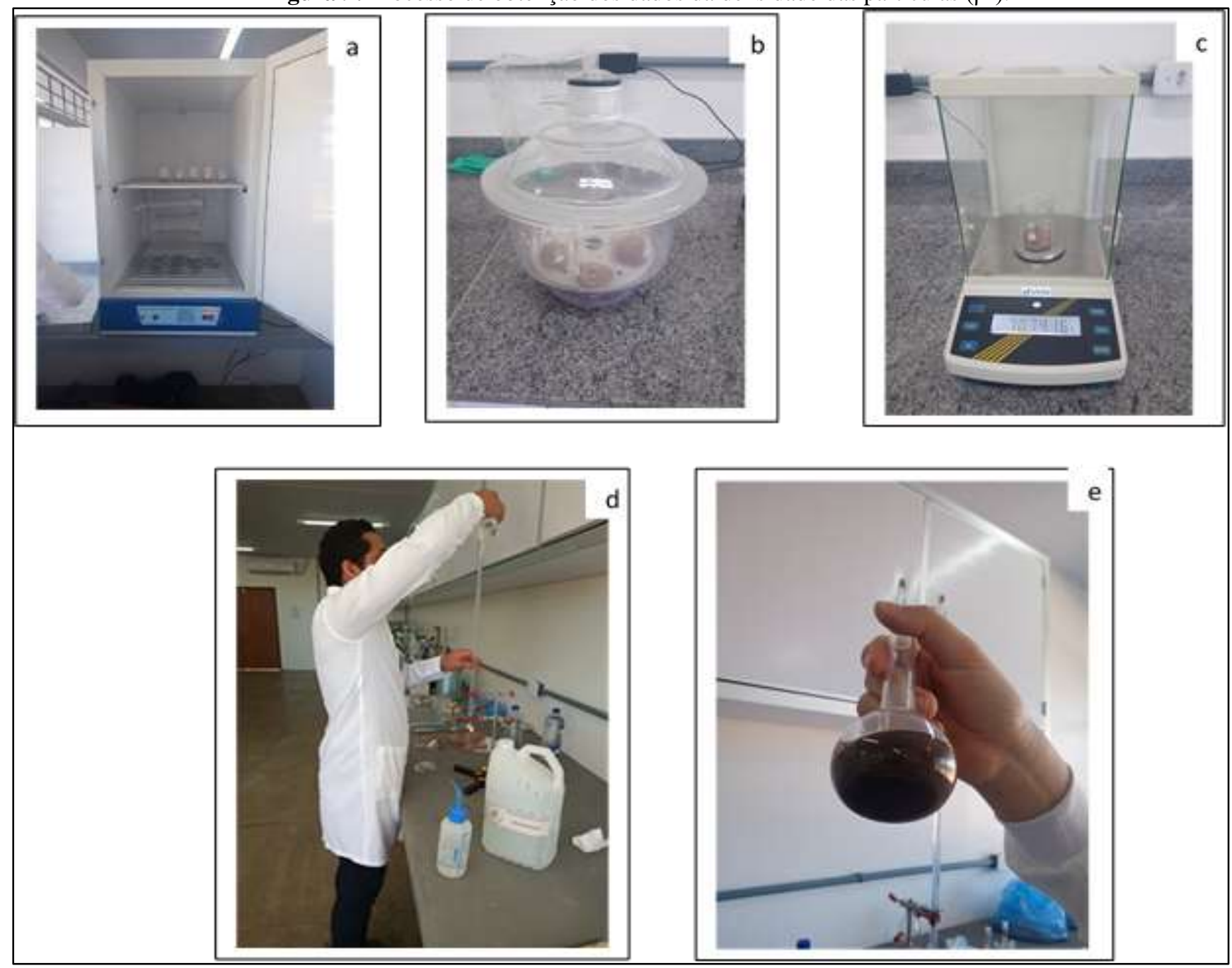

Fonte: Autores (2021).

Uma vez conhecido a massa de sólidos seco $\left(M_{S}\right)$ e o volume ocupado pelos sólidos $\left(V_{S}\right)$, a densidade dos sólidos do solo foi calculada pela seguinte equação (Eq. 1):

$$
\rho_{s}=\frac{M_{S}}{V_{S}}\left(K g m^{-3}\right)
$$

\section{- Densidade do solo $(\rho)$}

A densidade do solo $(\rho)$ foi determinada pelo método do torrão parafinado (EMBRAPA, 2017). O princípio desta metodologia se baseia na obtenção da massa por pesagem e do volume pelo deslocamento de líquido após a impermeabilização de um torrão com parafina fundida.

No momento da amostragem, em cada ponto foram selecionados torrões que tinham entre de $4 \mathrm{~cm}$ a $7 \mathrm{~cm}$ de diâmetro (pelo menos três para cada ponto) nas camadas de 0-10 cm e de 10-20 cm e no laboratório, eles foram secos ao ar. 
Para impermeabilização, os torrões foram amarrados a barbantes com etiquetas de identificação (Figura 10a e 10b). Em seguida, os torrões foram mergulhados em parafina fundida, cuidando-se para que fossem completamente recobertos e impermeabilizados por ela (Figura 10c).

Entre os materiais utilizados estão:

- Parafina sólida.

- Balança com precisão;

- Placa aquecedora;

- Béquer graduado de 0,5 L;

- Recipiente de metal ou vidro temperado para fusão da parafina;

- Estufa com ajuste de temperatura para 105;

- Dessecador;

Figura 10: Processo de obtenção dos dados da densidade do solo $(\rho)$.

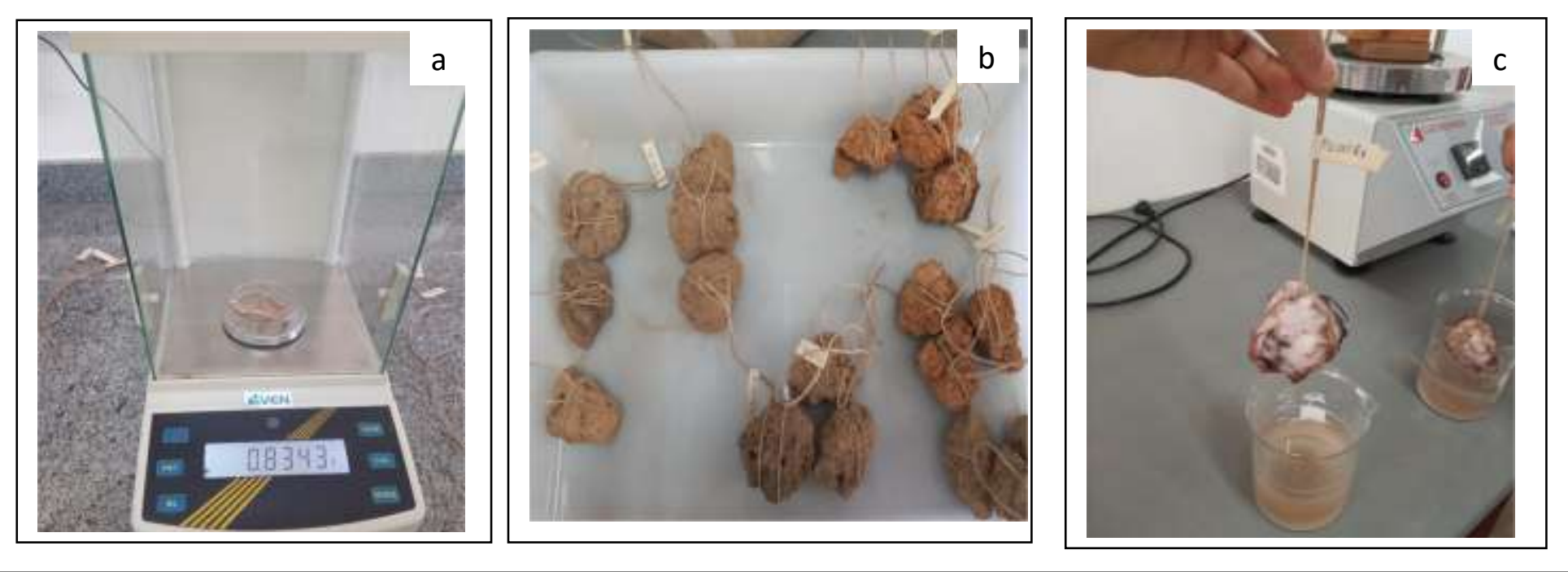

Fonte: Autores (2021).

Para determinar o volume de cada torrão utilizou-se um béquer graduado de volume suficiente de modo que o torrão parafinado coubesse inteiramente dentro dele. Primeiramente, foi feito a aferição do volume máximo que o béquer poderia conter, isto é, até o momento em que primeira gota de água estivesse próxima a cair pela abertura da vidraria.

Uma vez o béquer aferido, fez-se o mesmo procedimento de aferição do volume do béquer, mas desta vez, com o torrão dentro do béquer. Dessa forma, o volume que o torrão ocupava foi conhecido pela diferença entre o volume aferido do béquer inicialmente e o volume aferido com o torrão dentro deste.

Uma vez feito a aferição dos volumes dos torrões, retirou-se a parafina sobre estes e transferiu-se, sem resíduos da parafina, para uma lata de alumínio, para a secagem em estufa a $105^{\circ} \mathrm{C}$ até peso constante.

Uma vez desenvolvido todo procedimento laboratorial, a densidade do solo foi calculada pela seguinte equação recomendado por Embrapa (2017) (Eq. 6):

$$
P_{\text {tor }}=\left(\frac{m_{t u}}{1+b}\right)
$$




$$
\begin{gathered}
P_{\text {parafina }}=\left(m_{t p}+m_{\text {tor }}\right) \\
V_{\text {parafina }}=\frac{P_{\text {parafina }}}{0,9} \\
V_{\text {tor }}=\left[\left(V_{a}-V_{\text {at }}\right)-V_{\text {parafina }}\right] \\
\rho_{s}=\frac{P_{\text {tor }}}{V_{\text {tor }}}
\end{gathered}
$$

Em que:

$\mathrm{P}_{\text {tor }}$ - massa do torrão seco a $105^{\circ} \mathrm{C}, \mathrm{em} \mathrm{kg}$;

$\mathrm{m}_{\mathrm{tu}}$ - massa do torrão úmido, em $\mathrm{kg}$;

$\mathrm{b}$ - umidade da subamostra, em $\mathrm{kg} \mathrm{kg}^{-1}$;

$\mathrm{P}_{\text {parafina }}$ - massa da parafina, em $\mathrm{kg}$;

$\mathrm{V}_{\text {parafina }}$ - volume da parafina, $\mathrm{em} \mathrm{m}^{3}$;

$\mathrm{m}_{\mathrm{tp}}$ - massa do torrão parafinado, em kg;

$\mathrm{m}_{\text {tor }}-$ massa do torrão seco ao ar, em kg;

$\mathrm{V}_{\text {tor }}$ - volume do torrão, em $\mathrm{m}^{3}$;

$\mathrm{V}_{\mathrm{a}}$ - volume total de água do béquer, em $\mathrm{m}^{3}$;

$\mathrm{V}_{\mathrm{at}}$ - volume de água adicionado ao béquer com o torrão $\left(\mathrm{m}^{3}\right)$;

$\mathrm{V}_{\text {parafina }}$ - volume da parafina, $\mathrm{em}^{3}$.

- Porosidade do solo $(\alpha)$

Uma vez determinada a densidade do solo e a densidade dos sólidos, calculou-se a porosidade ( $\alpha$ ) do solo (Eq. 7):

$$
\alpha=\left(1-\frac{\rho}{\rho_{s}}\right) \times 100 \quad(\%)
$$

\section{- Diagnóstico rápido da estrutura do solo (DRES)}

Nos mesmos pontos onde as amostras foram coletadas foi (Pontos 1, 2 e 3) foi realizado o diagnóstico rápido da estrutura do solo (DRES) (EMBRAPA, 2017). O DRES é um método para qualificar a estrutura da camada superficial do solo, baseado em características detectadas visualmente em amostras dos primeiros $25 \mathrm{~cm}$ de profundidade.

As avaliações nas amostras constam da observação de tamanho e forma dos agregados e torrões, presença ou não de feições de compactação ou outra modalidade de degradação do solo, forma e orientação das fissuras, rugosidade das faces de ruptura, resistência à ruptura, distribuição e aspecto do sistema radicular, e evidências de atividade biológica. A partir desses critérios, atribui-se uma pontuação de 1 a 6 , onde "6" é indicativo de melhor condição estrutural, e "1" representa o solo totalmente degradado.

Com auxílio de uma enxada foi aberto mini-trincheiras de $40 \mathrm{~cm}$ de comprimento e $30 \mathrm{~cm}$ de largura (Figura 11). Em seguida, utilizando uma pá reta, extraiu-se blocos de solo com $10 \mathrm{~cm}$ de espessura e $25 \mathrm{~cm}$ de profundidade (Figura 12). 
Figura 11: Mini-trincheiras para extração de blocos superficiais e qualificação da estrutura do solo.

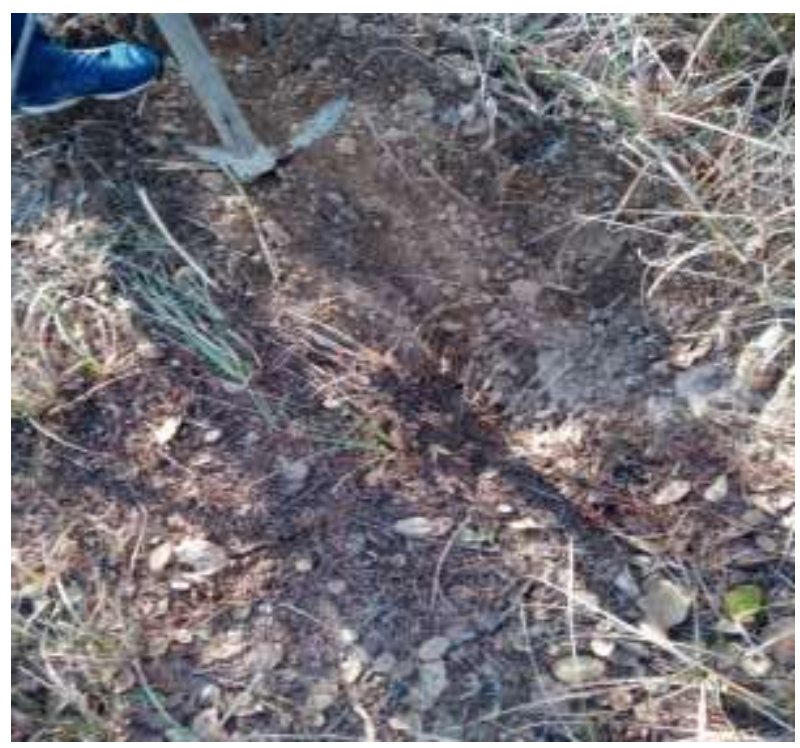

Fonte: Autores (2021).

Extraiu-se os blocos de solo com espessura de 10 a $20 \mathrm{~cm}$ e $25 \mathrm{~cm}$ de profundidade (Figura 12);

Figura 12: Extração dos blocos de solo com $10 \mathrm{~cm}$ de espessura e $25 \mathrm{~cm}$ de profundidade para avaliação do Diagnóstico Rápido da Estrutura do Solo (DRES).

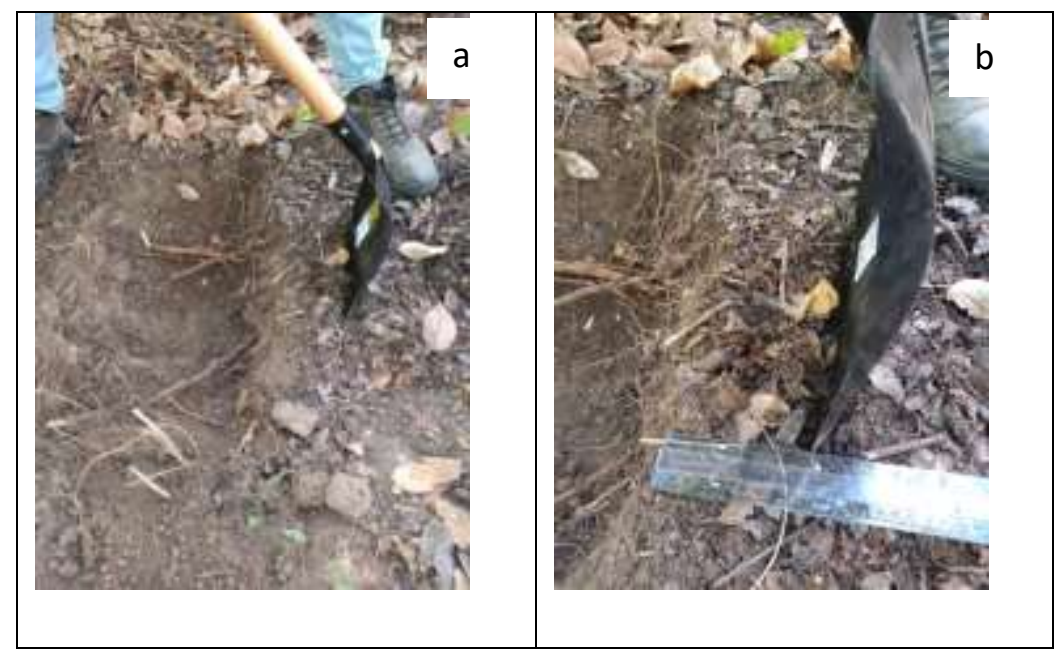

Fonte: Autores (2021).

Os blocos de solo foram cuidadosamente colocados em bandejas de plástico onde foi realizado a fragmentação dos agregados de solo em suas superfícies de fraqueza, obtendo agregados menores (Figura 13), tentando identificar diferenciação entre as camadas de solo (separadas pelas réguas na horizontal).

Atribuiu-se notas de qualidade estrutural da camada de solo (Qec) ali mesmo no local, usando a chave de classificação disponível em EMBRAPA (2017) (Figura 14); As notas de Qec foram atribuídas a partir da observação de evidências de feições de degradação ou conservação/recuperação do solo. 
Figura 13: Medição e fragmentação dos blocos de amostragem.

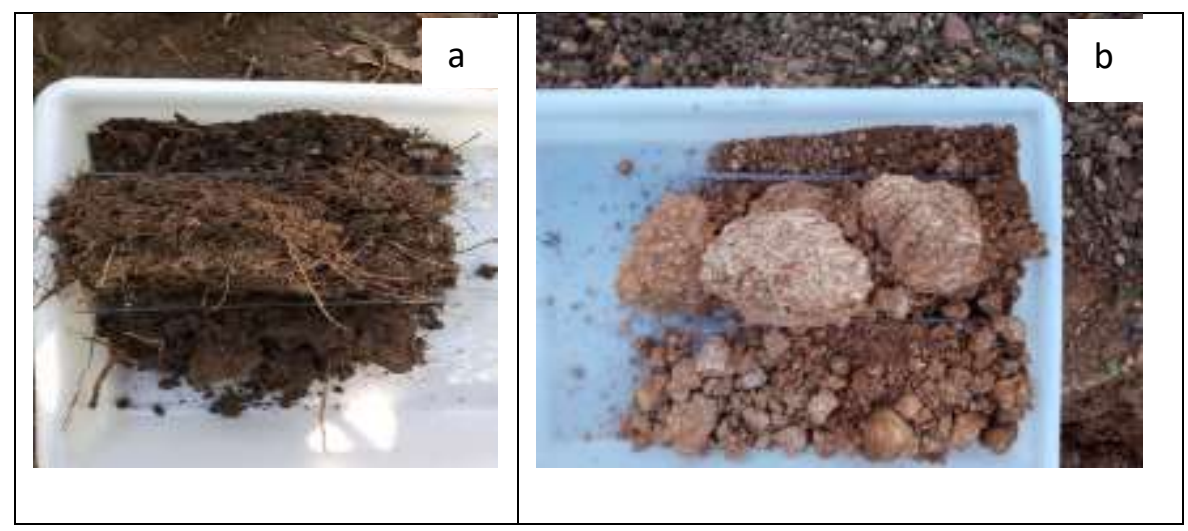

Fonte: Autores (2021).

Figura 14: Atribuição de notas de qualidade estrutural da camada de solo.

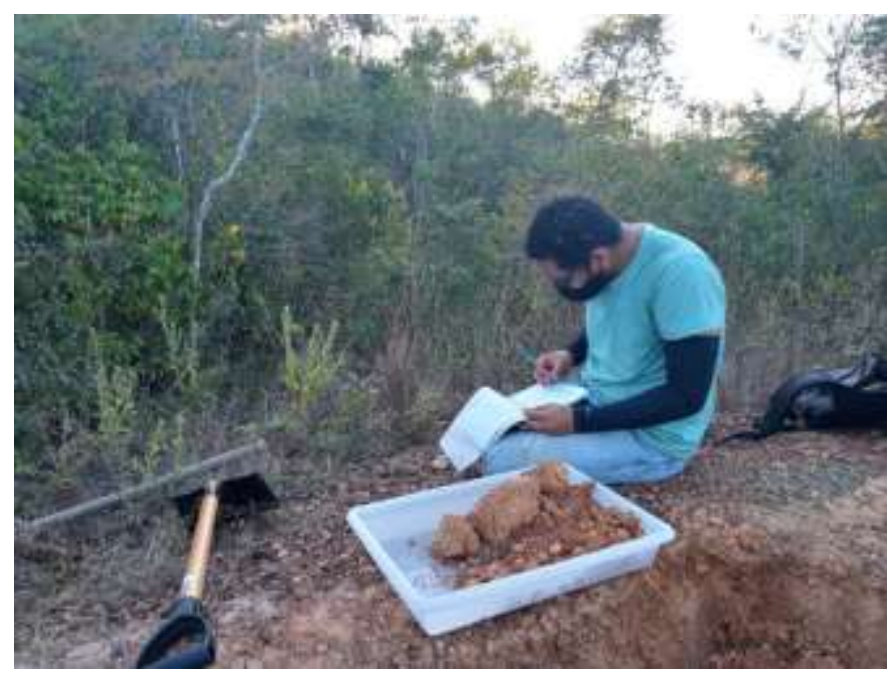

Fonte: Autores (2021).

A partir desses dados, calculou-se o Índice de qualidade estrutural de amostra do solo (IQEA) e o Índice de qualidade estrutural do solo (IQES), equações (8) e (9), respectivamente:

$$
\begin{gathered}
I Q E A=\frac{\left(\mathrm{Ec}_{1} \cdot \mathrm{Qe}_{1}\right)+\left(\mathrm{Ec}_{2} \cdot \mathrm{Qe}_{2}\right)\left(\mathrm{Ec}_{3} \cdot \mathrm{Qe}_{3}\right)}{E_{\text {total }}}, \\
I Q E S=\frac{\left(\mathrm{IQEA}_{1}\right)+\left(\mathrm{IQEA}_{2}\right)\left(\mathrm{IQEA}_{3}\right)}{n},
\end{gathered}
$$

\section{Em que:}

EC - espessura de cada camada, em cm (o número de camadas pode variar de 1 a 3);

Qec - nota de qualidade estrutural atribuída a cada camada;

$\mathrm{E}_{\text {total }}$ - espessura/profundidade total da amostra (padronizada em $25 \mathrm{~cm}$ ).

IQES - índice de qualidade estrutural do solo na área/gleba avaliada;

IQEA - nota de qualidade estrutural atribuída às amostras, de 1 até n.

$\mathrm{n}$ - número total de amostras. 


\section{- Carbono Orgânico Total}

O teor de carbono orgânico (CO) foi determinado em pelo método Walkey-Black (Anderson; Ingram, 1992). O método baseia-se na oxidação do carbono orgânico do solo com solução de dicromato de potássio em presença de ácido sulfúrico, usando o calor gerado pela diluição do ácido sulfúrico como catalizador da reação de oxirredução.

\subsection{Interpretação dos resultados}

Os resultados das análises da caracterização físico-estrutural do solo na área de estudo nas proximidades e margens do Rio Balsa foram analisados por meio de comparação com os padrões de qualidade de solo que foram obtidos com os registrados na literatura científica. $\mathrm{O}$ estudo foi discutido dessa forma devido não haver áreas em estado natural, isto é, que não sofreram degradação, representativa da área em estudo para que seja feito comparações.

A análise dos resultados foi feita de modo a expor as inter-relações existentes entre as propriedades físico-estruturais do solo como base para o entendimento dos processos de degradação ambiental presentes na área estudada e para a proposição das formas mais eficazes de recuperação dos danos observados.

Além disso é importante destacar que o trabalho possui uma metodologia do tipo quali-quanti avaliativa, pois ela é caracterizada pelas investigações realizadas por meio da coleta de dados e informações que foram recolhidas durante a pesquisa de campo juntamente com a orientadora do presente discente responsável pelo trabalho.

Para que seja mais compreensível e claro a especificação quanto à determinação desses dados, sempre será apresentado, incialmente, os dados em sua forma original, para que em nenhum momento ocorre-se a perda de dados. Em seguida é apresentado os mesmos dados já convertidos, possibilitando a compreensão sobre esse processo de conversão. Lembrando que as médias são para as densidades das partículas e densidades dos solos. Observe a Figura 15 a seguir.

Figura 15: Esquema para interpretação dos dados presentes nas tabelas.

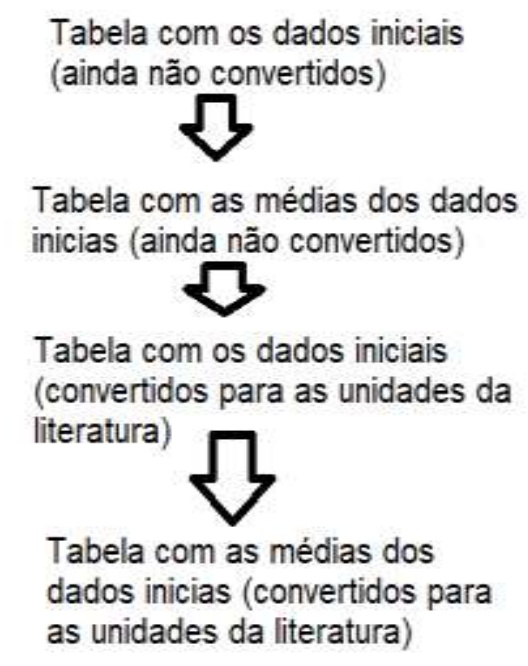

Fonte: Autores (2021).

Outro ponto importante é que o resultado final dado em função das médias, ocorreu por meio das repetições que foram realizadas para cada ponto nas camadas de $0-10 \mathrm{~cm}$ e de $10-20 \mathrm{~cm}$ e que contam nos anexos do presente trabalho. Cada ponto (1,2 e 3), conta com três repetições que após serem convertidas para se adequarem a literatura para análise dos resultados, são feitas as suas respectivas médias para cada ponto em análise. 


\section{Resultados e Discussão}

\subsection{Propriedades físico-estruturais do solo e carbono orgânico}

Os resultados da análise granulométrica para os pontos em que as amostras foram coletadas estão apresentados na Tabela 1. Verifica-se que não foi feito análise para comparação entre as profundidades de coleta, na verdade, as amostras das profundidades de 0,0 a $0,10 \mathrm{~m}$ e de 0,10 a $0,20 \mathrm{~m}$ de cada ponto coletado foram misturadas e obtidas uma amostra composta. Isso foi feito a partir do entendimento de que não haveria mudanças texturais importantes em função das profundidades de coleta que afetassem os atributos físico-estruturais do solo.

Tabela 1: Frações granulométricas do solo e classificação textural (0-10 e 10-20 cm foram misturadas).

\begin{tabular}{c|c|c|c|c}
\hline & Areia & Silte & Argila & Classe Textural \\
Amostras & $(\%)$ & $(\%)$ & $(\%)$ & Argilo Arenosa \\
próximo ao rio & 46 & 11 & 43 & Franco Argilo Arenosa \\
P2-Ponto intermediário de relevo & 56 & 11 & 33 & Franco Argiloso Arenosa \\
mais plano & & & & \\
P3-Ponto mais distante do rio de \\
relevo mais elevado
\end{tabular}

* Classificação segundo Embrapa (2006). Fonte: Terra Brasileira.

Verifica-se que em todos os pontos coletados houve predominância da fração areia, principalmente nos pontos 2 e 3 , e o ponto 1 apresentou maior teor da fração argila. O ponto 1 está localizado próximo à margem do rio, assim, quando este aumenta de nível ou mesmo devido à enxurrada, o material mais fino é mais facilmente depositado pela enxurrada, permanecendo a fração inorgânica mais fina. Este ponto se diferencia dos outro devido a presença da cobertura vegetal, elevada densidade de raízes e camada considerável de serrapilheira.

A partir da análise dessas condições locais, verifica-se que a cobertura do solo desempenha papel essencial para a manutenção da qualidade do solo, pelo aporte constante de matéria orgânica e ativação da atividade biológica no solo, principalmente para solos com teores intermediários da fração areia.

O ponto 2 está localizado numa região intermediária no terreno, há indícios de perda de material pela erosão, mas devido o seu relevo mais plano, comparado principalmente ao ponto 3, o material mais fino é perdido com menor intensidade.

Assim, verifica-se que, por mais que a textura do solo não seja facilmente alterável com manejo, os processos de adição de material oriundos de partes mais elevadas no relevo ativos no transporte (água e vento agindo diretamente na superfície do solo), explicam a maior proporção de argila nesse local (neste caso para o ponto 1-mais próximo ao rio).

A erosão do solo se constitui em um dos principais e mais severos processos de degradação do solo e causa danos tanto no local, quanto fora do local de origem, como também no local onde o material é depositado, podendo trazer contaminantes, pragas, causar o assoreamento de lagos e rios e ainda a eutrofização das águas (Magalhães, 2021).

Já o ponto 3, está localizado numa posição do relevo elevada e com processos erosivos em estágio avançado, evidenciados pela presença de várias voçorocas. Isso contribui para que o material mais fino, como as argilas e matéria orgânica, 
sejam facilmente perdidos para regiões mais baixas no terreno. Como o que foi relatado para o ponto 2, que provavelmente recebe os resíduos oriundos de locais mais altos do terreno, como este ponto analisado.

A seguir, são apresentados os resultados das propriedades fisico-estruturais do solo e carbono orgânico (Tabela 2). A densidade das partículas do solo $\left(\rho_{s}\right)$ é uma propriedade intrínseca do solo e reflete a sua constituição mineral, portanto, não é facilmente alterada pelas práticas adotadas na área.

Já a densidade do solo $(\rho)$, porosidade $(\alpha)$ e carbono orgânico do solo $(C O)$ são diretamente afetadas pelo manejo adotado nas áreas, de modo que, podem servir como indicadores da qualidade fisico-estrutural do solo e influenciar de forma indireta em outros atributos ambientais (Rosa, 2010).

Tabela 2: Propriedades físico-estruturais do solo e carbono orgânico total do solo.

\begin{tabular}{|c|c|c|c|c|}
\hline $\begin{array}{l}\text { Pontos de coleta/ profundidade } \\
(\mathrm{cm})\end{array}$ & $\begin{array}{c}\rho_{s} \\
\left(\mathrm{~kg} \mathrm{~m}^{-3}\right)\end{array}$ & $\begin{array}{c}\rho \\
\left(\mathrm{kg} \mathrm{m}^{-3}\right)\end{array}$ & $\begin{array}{c}\alpha \\
(\%)\end{array}$ & $\begin{array}{c}C O \\
\left(g k^{-1}\right)\end{array}$ \\
\hline \multicolumn{5}{|l|}{ P1-Ponto mais próximo ao rio } \\
\hline $0-10$ & 2304,88 & 949,8 & 58,79 & 21,9 \\
\hline $10-20$ & 2315,04 & 1130,72 & 51,15 & 14,7 \\
\hline \multicolumn{5}{|l|}{$\begin{array}{l}\text { P2-Ponto intermediário de relevo } \\
\text { plano }\end{array}$} \\
\hline $0-10$ & 2228,59 & 1045,72 & 53,07 & 11,9 \\
\hline $10-20$ & 2239,06 & 1009,65 & 54,90 & 13,9 \\
\hline \multicolumn{5}{|l|}{$\begin{array}{l}\text { P3-Ponto mais distante do rio de } \\
\text { relevo elevado }\end{array}$} \\
\hline $0-10$ & 2151,68 & 1056,45 & 50,90 & 14,4 \\
\hline $10-20$ & 2274,98 & 1090,24 & 52,07 & 9,5 \\
\hline
\end{tabular}

$\rho_{s}-$ densidade das partículas do solo; $\rho$ - densidade do solo; $\alpha$ - porosidade do solo; $C O$ - carbono orgânico do solo. Fonte: Autores (2021).

A densidade de partículas $\left(\rho_{s}\right)$ refere-se apenas à fração sólida de uma amostra de terra, sem considerar a porosidade. Por definição, entende-se como densidade das partículas a relação existente entre a massa de uma amostra de solo e o volume ocupado por esta fração sólida. De acordo com Cooper e Mazza (2021), de modo geral, para solos tropicais, $\rho_{s}$ tem um valor médio de $2650 \mathrm{~kg} \mathrm{~m}^{-3}$. Esse valor foi obtido a partir da densidade dos principais minerais presentes nos solos sob condições tropicais, como por exemplo, quartzo, feldspatos, micas e minerais de argila.

Verifica-se que em todos os pontos e profundidades estudadas $\rho_{s}$ apresentou valores inferiores à média considerada para os solos tropicais e que seus valores estão relacionados à constituição mineral desses solos. O ponto 1 na camada de $0-10 \mathrm{~cm}$ possui um valor médio de $\rho_{s}$ de $2304,88 \mathrm{~kg} / \mathrm{m}^{3}$ e na camada de $10-20 \mathrm{~cm}$ possui um valor médio de $2315,04 \mathrm{~kg} / \mathrm{m}^{3} ;$ O ponto 2 possui em sua camada de 0-10 cm um valor médio de $2228,59 \mathrm{~kg} / \mathrm{m}^{3}$ e na camada de $10-20 \mathrm{~cm}$ um valor médio de 2239,06 $\mathrm{kg} / \mathrm{m}^{3}$; Já o ponto 3, apresentou um valor médio de $2151,68 \mathrm{~kg} / \mathrm{m}^{3}$ para a camada de $0-10 \mathrm{~cm}$ e de $2274,98 \mathrm{~kg} / \mathrm{m}^{3}$ para a camada de $10-20 \mathrm{~cm}$.

De modo geral os valores de $\rho$ para os pontos analisados não mostraram indício de compactação do solo. No ponto de coleta 1, camada superficial (0-10 cm e 10-20 cm), a $\rho$ determinada foi de $949,80 \mathrm{~kg} \mathrm{~m}^{-3}$, mostrando a forte influência do material orgânico na organização estrutural do solo, reduzindo o valor da $\rho$. Além disso, a presença de raízes e atividade dos organismos do solo podem também contribuir um valor de $\rho$ menor (Neves, 2007). 
Para os demais pontos e camadas estudadas, verifica-se valores de $\rho$ correspondentes a camadas com constituição mineral predominante, com valores considerados baixos para a maioria dos solos tropicais (Neves, 2007).

O método do "Torrão Parafinado" geralmente é empregado em locais onde não é possível obter amostras de solo indeformada utilizando anéis volumétricos (Método do Anel Volumétrico), mas infelizmente a Instituição não possuía o equipamento no momento da realização das amostragens, optando-se então por esta metodologia. É importante destacar que todos os procedimentos laboratoriais foram seguidos com a maior zelo e atenção possível para evitar erros.

De maneira geral, pode-se afirmar que, quanto mais elevada for a densidade do solo, maior será sua compactação e a estrutura, menor sua porosidade total e, consequentemente, maiores serão as restrições para o crescimento do sistema radicular e desenvolvimento das plantas (Rosa, 2010).

Para uma condição de solo ideal, o espaço poroso do solo deve ser próximo a 50 \% (Melloni, 2008), o que favorece os fluxos de água, gases e calor no solo, assim como a presença de ambiente aeróbico para que a maioria dos organismos possam se desenvolver atuar melhorando a organização estrutural do solo. Ao observar os valores de $\alpha$ para todos os pontos, verifica-se resultados bons, a partir da referência acima, com destaque para a camada superficial do ponto 1, em que o valores de $\alpha$ foi $58,7 \%$, devido a presença da cobertura viva e morta mantida nesse local e ao constante aporte de matéria orgânica ao solo.

O carbono orgânico total (COT) do solo tem papel essencial para boa qualidade física e estrutural do solo. O CO do solo é favorecido pela manutenção da cobertura do solo (viva e morta), pelo não-revolvimento, presença dos organismos vivos e diversidade das raízes (Magalhães, 2021). Assim, ao analisar os resultados de COT para os solos estudados, verifica-se que as condições observadas no ponto 1 corroboram os valores superiores observados, principalmente na superfície do solo. Assim, pode-se afirmar que o primeiro passo se ao tentar recuperar uma área degradada, é recompor a cobertura do solo, pois além da proteção contra os agentes erosivos, também é aumentado o aporte de material orgânico ao solo, contribuindo para aumento da diversidade de vida no local, redução da densidade do solo e aumento da porosidade. Além disso, pode-se dizer, que com o aumento dos teores de COT há contribuição direta para o aumento da capacidade de troca catiônica (CTC), melhorando assim a retenção de água e disponibilidade de nutrientes (Rosa, 2010).

Os valores de COT para os demais pontos (2 e 3), considerando as condições de degradação observadas nas áreas, não foram baixos. É interessante observar que no ponto 2, a camada subsuperficial de 0-10 e 10-20 cm, apresentou teor de COT superior à camada sobrejacente. Isso pode ser explicado devido à constante deposição de material oriundo da parte superior do terreno.

\subsection{Diagnóstico rápido da estrutura do solo - DRES}

O diagnóstico rápido da estrutura do solo (DRES) foi obtido por meio da chave de atribuição de notas que consta no Anexo C do presente trabalho. Primeiramente, cada camada do solo identificada no bloco de solo coletado recebeu uma nota $\mathrm{Qe}_{\mathrm{c}}$ (nota de qualidade estrutural atribuída à camada). Em seguida, por meio da equação (8) foi calculado o IQEA (índice de qualidade estrutural atribuída à amostra). Em seguida, são apresentadas tabelas com as notas de qualidade para cada ponto estudado (P1, P2, P3): 
Tabela 3:Índice de qualidade estrutural do solo do Ponto 1.

\begin{tabular}{lccc}
\hline & AP1 (6 cm) & AP2 (13 cm) & AP3 (9 cm) \\
\hline Qe $_{\mathrm{c}}$ & 6 & 6 & 5 \\
Menor que 1 cm & $\mathbf{X}$ & & $\mathbf{X}$ \\
Entre 1 e $4 \mathrm{~cm}$ & & $\mathbf{X}$ & \\
Igual ou maior que 7 cm & $6 \mathrm{~cm}$ & $13 \mathrm{~cm}$ & $9 \mathrm{~cm}$ \\
Espessura da camada & & & $\mathbf{5 , 6 7}$ \\
IQEA do ponto 1 & & & \\
\hline
\end{tabular}

AP1, AP2, e AP3 são as camadas do solo que foram avaliadas; $\mathrm{Qe}_{\mathrm{c}}$ - nota de qualidade estrutural atribuída à camada; IQEA - Índice de qualidade estrutural atribuída à amostra.

Para o ponto 1, verifica-se notas de qualidade estrutural muito boas (Tabela 3). Para a primeira e terceira camada dos blocos analisados (AP1 e AP3), verifica-se que havia uma predominância de pelo menos $70 \%$ de agregados entre 1 e $4 \mathrm{~cm}$ e está relacionado a uma estrutura friável, agregados grumosos e porosos e com atividade biológica alta e presença abundante de raízes.

Na segunda camada do bloco (AP2), verificou-se uma intensa atuação das raízes das plantas, o que fez com que os agregados dessa camada fossem classificados dentro da faixa de tamanho superior a $7 \mathrm{~cm}$. Em outra condição, isso seria um indicativo de severa degradação do solo, mas em áreas com raízes abundantes, a agregação do solo pode se dar muito mais pela ação do emaranhado de raízes do que pela coesão entre partículas minerais do solo (isso ocorre em função da predominância da fração areia), formando "blocos" com muitos agregados fortemente unidos pelas raízes (EMBRAPA, 2017), como pode ser visto na Figura (16).

Figura 16: Agregados de solo formado pelas raízes das plantas (P1-Ponto próximo ao rio).

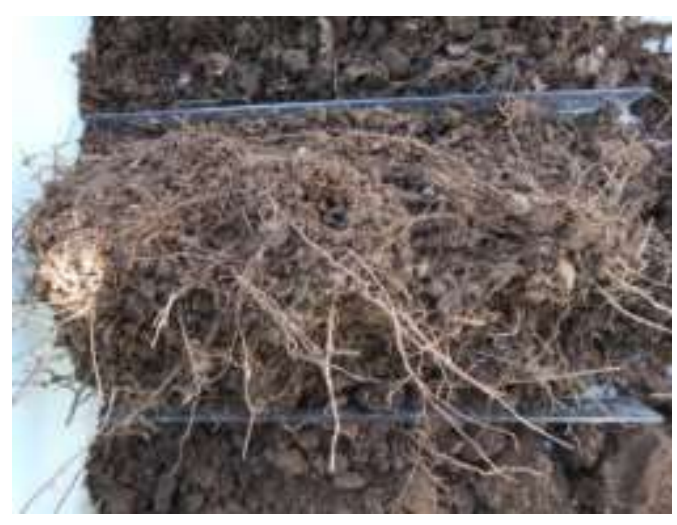

Fonte: Autores (2021).

O valor do IQEA obtido no ponto de coleta P1 foi 5,67, próximo da nota máxima de qualidade estrutural da chave utilizada (EMBRAPA, 2017). Isso indica, por essa análise, que o solo no ponto de coleta P1 apresenta qualidade estrutural do solo muito boa, o que pode ser verificado pelas condições locais de boa cobertura do solo, manutenção da vegetação típica local, atividade biológica intensa e boa densidade e diversidade de raízes no local.

A seguir, apresenta-se a Tabela o DRES para o ponto de coleta P2. Verifica-se que foram identificadas apenas duas camadas no bloco de solo. Isso aconteceu devido à dificuldade de extração do bloco e pela presença de pedras e pedregulhos nessa área de estudo. 
Tabela 4: Índice de qualidade estrutural do solo do Ponto 2.

\begin{tabular}{|c|c|c|c|}
\hline & AP1 & AP2 & \\
\hline $\mathrm{Qe}_{\mathrm{c}}$ & 3 & 1 & \\
\hline \multicolumn{4}{|l|}{ Menor que $1 \mathrm{~cm}$} \\
\hline Entre $1 \mathrm{e} 4 \mathrm{~cm}$ & $\mathbf{X}$ & & \\
\hline Igual ou maior que $7 \mathrm{~cm}$ & & $\mathbf{X}$ & \\
\hline Espessura da camada & $10 \mathrm{~cm}$ & $8 \mathrm{~cm}$ & \\
\hline IQEA do ponto 2 & & & 2,1 \\
\hline
\end{tabular}

AP1, AP2 são as camadas do solo que foram avaliadas; $Q_{c}$ - nota de qualidade estrutural atribuída à camada; IQEA - Índice de qualidade estrutural atribuída à amostra.

Verifica-se o que valor do $\mathrm{Qe}_{\mathrm{c}}$ para a camada AP1 é 3, indicando que menos de $50 \%$ dos agregados desse solo eram menores que $1 \mathrm{~cm}$ e maiores que $7 \mathrm{~cm}$, indicando que essa camada apresentava estrutura coesa nos agregados grandes e muito solta nos agregados menores. Havia também predomínio de agregados com faces planas, com poucos poros e pouco indicativo de atividade biológica. Para a camada AP2, a nota de $\mathrm{Qe}_{\mathrm{c}}$ foi inferior à da AP1, recebendo nota 1, indicando que mais de 70\% dos agregados dessa camada eram menores que $1 \mathrm{~cm}$ ou maiores $7 \mathrm{~cm}$. Essa nota indica a pouca qualidade estrutural desse solo, com predomínio de agregados com faces planas com restrição ao desenvolvimento radicular.

O índice IQEA calculado foi 2,1, conforme mostrado na Tabela 4, o que indica que o solo apresenta qualidade estrutural muito baixa, possivelmente oriunda dos processos de degradação da área estudada. Este resultado está de acordo com o que foi observado no local. A vegetação mostra-se em recuperação de eventos degradativos anteriores, o que pode ter contribuído diretamente para avaliação obtida por esta metodologia. Sendo assim, as recomendações de melhoria, com base nesse índice, sugerem que a necessidade de se realizar um diagnóstico da área mais bem detalhado, incluindo as condições físicas e químicas do solo e a adoção de modelos recuperação ambiental que acelerem o processo de sucessão natural e recomponham a cobertura vegetal do local, consequente proteção da superfície do solo contra os agentes erosivos e aumento do aporte de matéria orgânica.

O índice de qualidade estrutural para o ponto 3 (Tabela 5) quantificado como o menor possível, obtendo-se nota mínima em todas as camadas do bloco analisado.

Tabela 5: Índice de qualidade estrutural do solo do Ponto 3.

\begin{tabular}{lccc}
\hline & AP1 & AP2 & AP3 \\
Qe $_{\mathrm{c}}$ & 1 & 1 & 1 \\
Menor que $1 \mathrm{~cm}$ & & & $\mathbf{X}$ \\
Entre $1 \mathrm{e} 4 \mathrm{~cm}$ & & $\mathbf{X}$ & $\mathbf{1 5} \mathrm{cm}$ \\
Igual ou maior que $7 \mathrm{~cm}$ & $\mathbf{X}$ & $15 \mathrm{~cm}$ & $\mathbf{1 , 0}$ \\
Espessura da camada & $4 \mathrm{~cm}$ & & $\mathbf{1 0}$ \\
IQEA do ponto 3 & & & \\
\hline
\end{tabular}

AP1, AP2 são as camadas do solo que foram avaliadas. $Q_{\mathcal{c}}$ - nota de qualidade estrutural atribuída à camada; IQEA - Índice de qualidade estrutural atribuída à amostra.

Para o Ponto 3, observa-se que as notas estão totalmente de acordo com o que foi observado no local de estudo. Esse ponto encontra-se totalmente degradado, principalmente pela erosão que já levou boa parte da camada superficial do solo. Em toda área ao entorno do local estudado, verifica-se a presença de voçorocas e sulcos que provavelmente também evoluirão para 
esse estágio mais avançado. Não há presença de cobertura vegetal no local ou atuação de organismos vivos. Nesse sentido, verifica-se que esse ponto apresenta-se com severidade de degradação ambiental, necessitando, para sua preservação medidas mecânicas de contenção das voçorocas e ao mesmo técnicas de recuperação que tentem recompor a cobertura do solo.

\section{Considerações Finais}

A avaliação das propriedades fisico-estruturais do solo por meio da determinação da textura, densidade das partículas do solo, densidade do solo e cálculo da porosidade do solo indicam uma qualidade física e estrutural superior para o ponto P1, em que a vegetação local estava preserva com aporte constante de material orgânico e atividade biológica ativa (este último item avaliado de forma avaliativa). Porém, os dados para os pontos P2 e P3 não mostraram a severidade da degradação observada no local, necessitando, portanto, de uma análise mais aprofundada em relação a essas propriedades do solo do local e, se possível, inserir outras variáveis e sua inter-relações, inclusive por métodos diferentes.

O Diagnóstico Rápido da Estrutura do Solo (DRES) mostrou-se como uma ferramenta importante para avaliação da qualidade estrutural dos solos dos locais estudados, mostrando coerência com as condições de degradação observadas nas áreas de estudo. Por meio dessa técnica também foi possível comprovar a qualidade estrutural superior do ponto de coleta P1-Próximo ao rio em relação aos P2-ponto intermediário e P3-Ponto mais distante de relevo elevado, mas diferente da avaliação de atributos fisico-estruturais, mostrou a degradação avançada que esses dois últimos ponto se encontram.

A partir da avaliação das propriedades físico-estruturais dos solos estudados, verifica-se que existe qualidade estrutural levemente superior para o local onde a cobertura do solo é mantida, contribuindo para a proteção do solo quanto aos agentes de degradação. Neste sentido, reitera-se a importância da recuperação e conservação da vegetação local para proteção do solo e rio adjacente à área de estudo. Caso contrário, o cenário observado atualmente pode ser ainda mais agravado e esses pontos estudados poderão ser acometidos com maior intensidade pelos agentes ativos (água e vento) e consequentemente os seus respectivos resultados em curto espaço de tempo.

Recomenda-se que para trabalhos futuros, sejam realizados estudos sobre a dinâmica da água no solo, como a curva de retenção da água no solo e condutividade hidráulica do solo saturado e não saturado, uma vez que são propriedades que refletem diretamente a qualidade estrutural do solo. Para além disso, estudos que identifiquem as melhores estratégias de recuperação da área degradada também devem ser desenvolvidos, identificando as melhores técnicas para interromper os processos de degradação observados na área e também de recuperação das áreas afetadas.

\section{Referências}

Almeida, Fabiane Gonçalves. et al. (2019). Conservação do solo e água no brasil: no contexto agrícola e ambiental. Revista Vozes dos Vales - UFVJM. 16(VIII). Reg.: 120.2.095-2011 - UFVJM - QUALIS/CAPES - LATINDEX - ISSN: 2238-6424.

http://site.ufvjm.edu.br/revistamultidisciplinar/files/2019/10/Rafael.pdf.

Anderson, J. M \& Ingram, J.S.I. (1992). Tropical soil biology and fertility: a handbook of methods. Wallingford: CAB International. 171p.

Andrade, A.G \& Portocarrero, H. \& Capeche, C. C. (2005). Práticas Mecânicas e Vegetativas para Controle de Voçorocas. ISSN 1517-5685 Rio de Janeiro, RJ.

Branco, P.M. (2014). Os solos. http://www.cprm.gov.br/publique/CPRM-Divulga/Canal-Escola/Os-Solos-2620.html.

Brady, N.C \& WeiL, R.R. (2013). Elementos da Natureza e Propiedades dos Solos. 3 ed. Porto Alegre: Editora Bookman. 716p.

Brasil. (2021). Ministério da Educação. Água e solos. Universidade Federal de Santa Maria. Curso de Pós-Graduação em Educação Ambiental. https://repositorio.ufsm.br/bitstream/handle/1/16188/Curso_Agric-Famil-Sustent_Agua-Solo.pdf?sequence=1\&isAllowed=y.

Brun, E. J. (2008) Matéria orgânica do solo em plantios de Pinus taeda e P. elliottii em duas regiões do Rio Grande do Sul. 118 f. Tese (Doutorado em Engenharia Florestal) - Universidade Federal de Santa Maria, Santa Maria.

CASTRO, M. (2013). Mecanização no campo muda as relações de trabalho.

https://www.em.com.br/app/noticia/economia/2013/01/14/internas_economia,343131/mecanizacao-no-campo-muda-as-relacoes-de-trabalho.shtml. 
CÉSAR, C. (2021) Matéria orgânica no solo e a utilização de resíduos na agricultura. https://www.embrapa.br/documents/1355242/3554062/Sinop+1.pdf/66cd6560714c-4e59-bc69-1671134ff2a9.

CETESB. Companhia Ambiental do Estado de São Paulo. (2021). Propriedades do solo. https://cetesb.sp.gov.br/solo/propriedades/.

COOPER, M. \& MAZZA, J. A. (2021). Densidade do solo e densidade das partículas. https://edisciplinas.usp.br/pluginfile.php/300387/mod_resource/content/0/Aula\%20Te\%C3\%B3rica\%203\%20-

$\% 20$ Densidade $\% 20$ do $\% 20$ Solo $\% 20 \mathrm{e} \% 20$ Densidade $\% 20 \mathrm{de} \% 20 \mathrm{Part} \% \mathrm{C} 3 \%$ ADcula.pdf\#: :text=Nos $\% 20$ solos $\% 2 \mathrm{C} \% 20$ seus $\% 20 \mathrm{valores} \% 20 \mathrm{variam}$,sendo $\% 20 \mathrm{~d}$ e\% $202 \% 2 \mathrm{C} 65 \% 20 \mathrm{~g}$.

EMBRAPA - Empresa Brasileira de Pesquisa Agropecuária Centro Nacional de Pesquisa de Solos. (2018). Sistema brasileiro de classificação de solos. 5. ed. Brasília, DF: Embrapa.

EMBRAPA - Empresa Brasileira de Pesquisa Agropecuária Centro Nacional de Pesquisa de Solos. (2017). Manual de métodos de análise do solo. $3^{\circ}$ adição revista e ampliada. Brasília-DF.

EMBRAPA - Empresa Brasileira de Pesquisa Agropecuária Centro Nacional de Pesquisa de Solos. (2018)A Visão da Ciência do Solo no Contexto do Diagnóstico, Manejo, Indicadores de monitoramento e Estratégias de Recuperação.

EMBRAPA - Empresa Brasileira de Pesquisa Agropecuária Centro Nacional de Pesquisa de Solos.(2018). Sistema brasileiro de classificação de solos. Rio de janeiro: Embrapa-CNPS.

EMBRAPA - Empresa Brasileira de Pesquisa Agropecuária Centro Nacional de Pesquisa de Solos. (2017). Manual de métodos de análise de solo / Paulo César Teixeira ... [et al.], editores técnicos. - 3. ed. rev. e ampl. - Brasília, DF : Embrapa. 574 p.

EMBRAPA - Empresa Brasileira de Pesquisa Agropecuária Centro Nacional de Pesquisa de Solos. (2017). Diagnóstico Rápido da Estrutura do Solo - DRES. Ralisch, Ricardo. II.Debiasi, Henrique. III. Franchini, Júlio Cezar. IV.Tomazi, Michely. V.Hernani, Luís Carlos. VI.Melo, Adoildo da Silva. VII.Santi, Anderson. VIII.Martins, Alba Leonor da Silva. IX.Bona, Fabiano Daniel de. $1^{\circ}$ Edição.

Filho, M. F. F \& Bueno, C. R .P \& Valladares, G. S. (2019). Caracterização e classificação de solos hidromórficos sobre os aluviões fluviomarinhos no município de Arari-Ma. https://revistas.ufpr.br/raega/article/view/61912/41295.

Formiga, J. N. (2021). História de Balsas-MA. http://recantodopoetabalsense.blogspot.com.br/p/conheca-balsas-ma.html.

FUNASA. Fundação Nacional de Saúde. (2013). Manual Prático de Análise de Água. http://www.funasa.gov.br/site/wpcontent/files_mf/manual_pratico_de_analise_de_agua_2.pdf. Brasília-DF.

Hillel, D.(1970). Solo e água: fenômenos e princípios físicos. Porto Alegre: Universidade Federal do Rio Grande do Sul. 231p.

IBGE-Instituto Brasileiro de Geografia e Estatística. (2021). Documentação do Censo 2021. Rio de Janeiro: IBGE, 2021.

IBGE-Instituto Brasileiro de Geografia e Estatística. (2010). Documentação do Censo 2010. Rio de Janeiro-RJ.

IGA-Instituto Agronômico de Pernanbuco. (2021). Conservação do solo- Prática de eficiente e controle da erosão http://www.ipa.br/resp9.php.

Klein, V. A \& Libardi, P. L. (2002). Densidade e distribuição do diâmetro dos poros de um latossolo vermelho, sob diferentes sistemas de uso e manejo. Revista Brasileira de Ciência do Solo, v. 26, n. 4, p. 857 - 867.

Lepsch, I. F. (2011). 19 lições de pedologia. São Paulo: Oficina de Texto.

Letey, J. (1985). Relationship between soil physical properties and crop productions. Advances in Soil Science, New York, v. 1, p. 277-294..

Lima, V.C \& Lima, M.R. (2008). Importância de estudar o solo. In: Solos para professores do ensino fundamental e médio. Curitiba: UFPR, Departamento de Solos e Engenharia Agrícola.

Magalhães, A. C. et al. (2021). A importância dos solos para o ecossistema.

https:/www.bibliotecaagptea.org.br/agricultura/solos/artigos/A\%20IMPORTANCIA\%20DOS\%20SOLOS\%20PARA\%20O\%20ECOSSISTEMA.pdf.

Martins, M. V, E. \& Lima, H. E \& Barbosa, L. P. \& Abreu, V. P. (2021). Análise da qualidade da água

superficial do córrego aurora de Balsas/Ma. Universidade

Federal do Maranhão-Campus Balsas. Departamento de Engenharia Ambiental. Disciplina de Laboratório de Qualidade de Água e Esgoto.

Melloni, R. et al (2008). Avaliação da qualidade de solos sob diferentes coberturas florestais e de pastagem no sul de Minas Gerais. Revista Brasileira de Ciência do Solo, Viçosa, v. 32, n. 6, p. 2461-2470, nov./dez.

Montes, M. L. (1997). Zoneamento geoambiental do estado do maranhão diretrizes gerais para a ordenação territorial. Ministério de Planejamento, Orçamento e Coordenação. Fundação Instituto Brasileiro de Geografia e Estatística- IBGE. Diretoria de Geociências-Divisão de Geociências da Bahia. https://biblioteca.ibge.gov.br/visualizacao/livros/liv95885.pdf .

Morgan, R. P. C.(2005). Soil Erosion and Conservation. 3. ed. England: Blackwell.

Neves, C. M. N. das et al. (2007). Atributos indicadores da qualidade do solo em sistema agrossilvopastoril no noroeste do estado de Minas Gerais. Scientia Forestalis, Piracicaba, n. 74, n. 2, p. 45-53, junho. 
Niero, L. A. C; dechen, S. C. F; coelho, R. M; maria, I. C. (2010). Avaliações visuais como índice de qualidade do solo e sua validação por análises físicas e químicas em um latossolo vermelho distroférrico com usos e manejos distintos. Revista Brasileira de Ciência do Solo, v. 34, n. 4, p. 1271-1282, jul./ago.

Novaes Filho J. P. \& Couto E.G. \& Oliveira V.A. \& Johnson M. S. \& Lehmann, J. \& Riha SS. (2007). Variabilidade espacial de atributos físicos de solo usada na identificação de classes pedológicas de microbacias na Amazônia meridional. Revista Brasileira de Ciência do Solo 31:91-100.

Oliveira D. P \& Artur A. G. \& Costa M. C. G \& Romer R. E. \& Silva M.V.C. \& Ferreira, T. O. (2014). Variabilidade espacial dos atributos químicos do solo, associada ao microrrelevo. Revista Brasileira de Engenharia Agrícola e Ambiental V. 18. p.141-149.

Oliveira, J. B. (2008). Pedologia aplicada. Piracicaba: FEALQ, 592 p.

Oliveira, J. B. \& Jacomine, P. K. T. \& Camargo, M. N. (1992). Classes gerais de solos do Brasil. 2.ed. Jaboticabal: FUNEP. 201 p.

Resende, M.; Curi, N.; Santana, D. P. (2015). Pedologia e fertilidade do solo: interações e aplicações. Brasília, DF: MEC; [Lavras].

Pereira, L. S. \& Jorge, M. C. O. \& Rodrigues, A. M. \& Guerra, A. J. T. Contribuição das chuvas de baixa intensidade nos processos erosivos superficiais em ambiente degradado bacia hidrográfica do rio Maranduba, Ubatuba/SP. Revista Equador (UFPI), v. 4, n. $3,2015$.

Pires, L. F. \& Reichardt, K. \& Cooper, M. \& Cássaro,F.A.M. \& Dias, N.M.P. \& Bacchi, O.O.S. (2009). Pore system changes of damaged Brazilian oxisols and nitosols induced by wet-dry cycles as seen in 2-D micromorphologic image analysis. Anais da Acadêmia Brasileira de Ciências, Rio de Janeiro, v. 81, $\mathrm{n}$. 1 , p. $151-161$.

Portal do Tratamento da Água. Qualidade da água. Disponível em: < https://tratamentodeagua.com.br/artigo/qualidade-da-agua/ >. Acesso em: 27 de Junho de 2021.

Primavesi. A. M. (2018). Manejo sadio dos solos. Vol. 05, nº 03. Revista Agriculturas. Disponível em: < file://C:/Users/vfede/Downloads/Agriculturas_v5n3\%20(1).pdf> Acesso em: 19 de Agosto de 2021.

Ramiro, J. (2019). Tipos de solo: saiba quais são e os tipos existentes no Brasil. https://boaspraticasagronomicas.com.br/artigos/tipos-de-solo/.

Ramos, V. et al. (2018). Conservação da Água e do Solo: O Caso do Sítio Panorama em Varre-Sai-RJ, Simpósio de Recursos Hídricos da Bacia do Rio Paraíba do Sul, Varre-Sai- RJ, p.1-10.

Ribeiro, L. \& Rolim, N. (2017). Planeta água de quem e para quem: uma análise da água doce como direito fundamental e sua valoração mercadológica Revista Direito Ambiental e sociedade, v. 7, n. 1, p. 02-35.

Rodrigues, P. P. (2021). Projeto de extensão ecossocial "formação profissional de agentes de reflorestamento. http://r1.ufrrj.br/cfar/d/download/Relacao\%20solo\%20agua\%20planta.pdf.

Rosa, S. F. (2010). Propriedades físicas e químicas de um solo arenoso sob o cultivo de Eucalyptus spp. Universidade Federal de Santa Maria. Centro de Ciências Rurais. Programa de Pós-Graduação em Engenharia Florestal. Dissertação de Mestrado. Santa Maria, http://www.fisicadosolo.ccr.ufsm.quoos.com.br/downloads/Suzana_Ferreira_Da_Rosa_Dissertacao.pdf.

Santos, F. \& Aquino, C. (2016). Panorama Da Desertificação No Nordeste Do Brasil: Características e suscetibilidades. Revista de Geografia e interdisciplinaridade, v.2, n.7, Grajaú-MA, set./dez.

Santos, H. G. et al. (2018). Sistema Brasileiro de Classificação de Solos. 5. ed., rev. e ampl. - Brasília, DF : Embrapa. ISBN 978-85-7035-800-4.

Santos, Sheila. (2021). Propriedades Físicas do Solo. Instituto de Ciência, Engenharia e Tecnologia. http://site.ufvjm.edu.br/icet/files/2016/08/Propriedadesf\% $3 \%$ ADsicas-do-solo.pdf.

Sousa, D.M.G \& Lobato, E. (2004). Cerrado: correção e adubação. Brasília, DF:Embrapa Informação tecnológica, 2.ed, p.147167.http://guaiaca.ufpel.edu.br:8080/bitstream/123456789/1369/1/dissertacao_rosidelma_da_silva_felicio_marin.pdf.

Souza, J, G. (1999). O Nordeste brasileiro: uma experiência de desenvolvimento regional. Fortaleza: Banco do Nordeste do Brasil. 410 p.

Sovis. (2018). Como a tecnologia no campo evoluiu até os dias de hoje?. https://sovis.com.br/blog/tecnologia-no-campo-evolucao/>.

TBLA-Terra Brasileira: Laboratório Agronômico. (2021). Análise de solo. https://tbrasileira.com.br/.

Toledo, M. C. M. et al. Intemperismo e Formação do Solo. In: Teixeira, W. et al. Decifrando a Terra. São Paulo, Oficina de Textos, 2000. 568p. Il. p. 139-166. il.

Tominaga, L. K. Avaliação de metodologias de análise de risco a escorregamentos: aplicação de um ensaio em Ubatuba, SP. Tese (doutorado) Universidade de São Paulo, 2007.

Tormena, C.A, \& Roloff, G. \& Sá, J.M.C. (1998). Propriedades físicas do solo sob plantio direto influenciadas por calagem, preparo inicial e tráfego. Revista Brasileira de Ciência do Solo, Viçosa, v. 22, p. 301 - 309.

Tullio, L. (org). Formação, classificação e cartografia dos solos. (2019). Ponta Grossa, PR: Atena Editora, 2019. https://www.atenaeditora.com.br/wpcontent/uploads/2019/09/E-book-Formacao-Classificacao-e-Cartografia-dos-Solos.pdf .

Van Lier, Q. J. (2010). Física do Solo. Viçosa: Sociedade Brasileira de Ciência do solo. 298 p.

Wadt, P. G. S. (2004). Recomendação de adubação para as principais culturas. (EMBRAPA-ACRE). Rio Branco-Acre.

Yoder, R.E. (2006). A direct method of aggregate analysis of soil and a study of the physical nature of erosion losses. Journal of America Society of Agronomy, v.28, p.337-357.

Zonta, E. \& Lima, E. \& Oliveira, C. \& Ceddia, M. B. (2007). Solos e Agricultura.(apostila). 